\title{
Volatiles and sensory evaluation of goat milk cheese Gokceada as affected by goat breeds (Gokceada and Turkish Saanen) and starter culture systems during ripening
}

\author{
A. A. Hayaloglu, ${ }^{* 1}$ C. Tolu, $†$ K. Yasar, $\ddagger$ and D. Sahingil* \\ *Department of Food Engineering, Inonu University, 44280 Malatya, Turkey \\ †Department of Animal Science, Canakkale Onsekiz Mart University, 17020 Canakkale, Turkey \\ ‡Department of Food Engineering, Osmaniye Korkut Ata University, 80000 Osmaniye, Turkey
}

\begin{abstract}
The effect of goat breed and starter culture on volatile composition and sensory scores in goat milk cheese was studied during $90 \mathrm{~d}$ of ripening. Milk from 2 goat breeds (Gokceada and Turkish Saanen) and different starter culture systems (no starter, mesophilic and thermophilic starters) were used in the manufacture of goat milk cheeses (called Gokceada goat cheese). Volatile composition was determined by a solid-phase microextraction-gas chromatography-mass spectrometric method. Sixty compounds including esters (13), carboxylic acids (7), aldehydes (6), ketones (8), alcohols (14), and miscellaneous compounds (12) were identified. Esters, alcohols, and carboxylic acids were the main classes of volatile components in the cheeses. Both qualitatively and quantitatively, the use of different starter cultures and goat breeds significantly influenced the volatile fraction of goat milk cheese. Decanoic, hexanoic, and octanoic (commonly named capric, caproic, and caprylic) acids were indicator compounds to distinguish the goat breeds. Principal component analysis grouped the cheeses based on the use of starter culture and goat breed. Starter-free cheeses were separately located on the plot and age-related changes were present in all samples. Sensory evaluation of 90-d-old cheeses showed that the cheeses from the Gokceada breed received higher odor, flavor, and quality scores than those from the Turkish Saanen breed, and cheeses made using mesophilic starters resulted in the most satisfactory scores for flavor and quality attributes. In conclusion, goat milk cheeses made using milk from Gokceada goats and mesophilic starter culture had the best quality in terms of volatile composition and sensory attributes.
\end{abstract}

Key words: goat cheese, volatile composition, sensory evaluation, ripening

Received September 17, 2012.

Accepted December 4, 2012.

${ }^{1}$ Corresponding author: adnan.hayaloglu@inonu.edu.tr

\section{INTRODUCTION}

Flavor compounds in foods play a critical role in their quality. The flavor of dairy foods, especially cheese, has been extensively studied; however, cheeses from goat milk have not been studied to the same extent as those from cow milk. Similarly, research is lacking on the characterization of chemistry, microbiology, and physics of cheeses made using goat milk (Carunchia Whetstine et al., 2003; Attaie, 2009). Cheese flavor is a result of a complex balance among volatile and nonvolatile chemical compounds from milk fat, milk proteins, and carbohydrates during the ripening of cheese (Fox and Wallace, 1997). The metabolism of residual lactose and lactic and citric acids produces flavor compounds such as acetate, acetaldehyde, ethanol, diacetyl, and acetoin (McSweeney and Sousa, 2000). Amino acids are converted by many different enzymatic pathways into, for example, aldehydes, alcohols, carboxylic acids, hydroxy acids, indole and sulfur compounds, ammonia, $\alpha$-keto acids, volatile amines and amides, and phenolic compounds (Engels et al., 1997; McSweeney and Sousa, 2000). Fatty acids are precursors in the formation of ketones, primary and secondary alcohols, $\delta$ - or $\gamma$-lactones, aldehydes, and aromatic and aliphatic esters (McSweeney and Sousa, 2000; Collins et al., 2003).

A large number of goat cheeses in Turkey are produced in villages, and industrial-scale production of goat cheeses is very limited. Some difficulties in goat production, decreases in the rural population of people, and a lack of published data on goat milk products have resulted in a lack of interest by the dairy industry. Many researchers have focused on cheeses made using cow milk, and the production and processing of goat milk products have been ignored. In recent years, demand from consumers and state support policies have encouraged the production of small ruminants; goat milk production is particularly encouraged by aid programs (Hayaloglu and Karagul-Yuceer, 2011). In general, raw goat milk has been used for the manufacture of goat milk cheeses in Turkey, with the exception of some mid- 
scale local cheese manufacturers. Gokceada goat cheese has been manufactured for years in Gokceada, an island near the Dardanelles (Turkey). The Gokceada breed has high milk yields, reported recently by Tolu (2009). Gokceada cheese is often consumed without ripening; however, the cheese is thought to gain its characteristic taste and flavor after 2 mo of ripening. Its manufacturing period is between April and August and cheeses are ripened for 2 to 6 mo (based on consumer preference; no regulation controls the ripening conditions). No starter culture is added to the cheese milk and calf rennet is traditionally used for coagulation. After coagulation of milk, the curd is drained in a cotton cloth and pressed with weights for about $6 \mathrm{~h}$. The pressing results in an oval-shaped curd, which is divided into 4 equal blocks weighing 300 to $500 \mathrm{~g}$. Coarse salt is sprinkled on the surface of the blocks and rested for 2 to $3 \mathrm{~d}$ in a plastic or earthenware container. After draining the serum from the cheese mass, the salted serum can be used as brine to ripen Gokceada goat cheese. After ripening for about $2 \mathrm{mo}$, the cheese has a harder texture with a salty and acidic taste.

Because of the lack of standards in manufacturing and ripening methods and the use of raw goat milk in production, the chemical and microbiological quality and the biochemical changes occurring during ripening are unpredictable. We aimed to produce Gokceada goat cheese using pasteurized milk with starter cultures. Milk from 2 breeds-Gokceada and Turkish Saanen-was used for the manufacture of Gokceada goat cheese. Differences in the chemical composition of the milk from 2 breeds and physiological factors may affect the quality of cheeses. Therefore, our hypothesis was that differences in milk composition may influence the volatile flavor composition of cheeses obtained from the 2 different breeds. Soryal et al. (2005) noted that cheese yield and gross chemical composition (milk fat, total protein, casein, and total solids) of milk obtained from Alpine and Nubian goat breeds were significantly different. In addition, the starter culture(s) used can change the volatile profiles of cheese. Ferreira et al. (2009) showed that cheeses made using milk from 3 breeds had different volatile and sensory profiles. We also used mesophilic and thermophilic starter cultures in the manufacture of Gokceada cheese and compared the resulting cheeses with starter-free counterparts. Effects of starter culture on cheese volatile fractions have been extensively studied in cheeses obtained from cow milk; however, studies on goat milk cheeses are scarce. At present, the need exists to characterize the volatile compounds in Gokceada goat cheese made using milk from different goat breeds and with different starter cultures. In this study, volatile profiles of Gokceada goat cheeses detected by GC-MS with solid-phase microextraction (SPME) were determined during $90 \mathrm{~d}$ of ripening, and sensory evaluation of the cheeses was conducted after $90 \mathrm{~d}$ of ripening.

\section{MATERIALS AND METHODS}

\section{Cheese Manufacture}

Experimental cheeses were manufactured in a private dairy plant (Imroz Co. Inc., Gokceada, Canakkale, Turkey) using the milk from 2 goat breeds, Gokceada and Turkish Saanen. Gokceada goats were reared in near-feral conditions on the island of Gokceada. The goats graze freely year round on the natural pastures of the island. The island is dominated by the Mediterranean climate and is heavily covered by Sarcopoterium spinosum (thorny burnet) and Astragalus species (e.g., milkvetch). The lactation period of these goats is from March to August. The Turkish Saanen breed was kept according to Turkish organic agricultural production rules. The goats grazed on barley pasture that was grown annually. Additionally, both breeds were provided with hay (alfalfa and vetch hays) and concentrate feed. The gross chemical composition of the milk from Gokceada and Turkish Saanen were 13.1 and $12.1 \%$ TS, 4.1 and $3.5 \%$ total protein, 4.4 and $3.5 \%$ for fat, and 0.9 and $0.7 \%$ ash content, respectively. Ninety kilograms of milk was obtained from each breed (180 kg in total). The milk from each breed was heat-treated at $65^{\circ} \mathrm{C}$ for 20 min and then divided into 3 parts to produce 3 types of cheese from each breed. Cheeses were manufactured with or without starter cultures. A mixture of Lactococcus lactis ssp. lactis and Lactococcus lactis ssp. cremoris (FD-DVS R-704, Peyma-Hansen, Istanbul, Turkey) was used as the mesophilic starter, and Streptococcus thermophilus (FD-DVSST-B01, Peyma-Hansen) was used as the thermophilic starter. Cheeses were manufactured using milk from the Gokceada breed by the addition of mesophilic (GM) or thermophilic (GT) starter and without starter culture (GK). Another group of cheeses was manufactured using milk from the Turkish Saanen breed by the addition of mesophilic (SM) or thermophilic (ST) starter and without starter culture (SK). Calf rennet (Ren-Na Ozel, Mayasan, Istanbul, Turkey) was used in the production (strength was $1 / 18,000=1$ $\mathrm{mL}$ of rennet per $18 \mathrm{~L}$ of milk). After coagulation of milk for about $90 \mathrm{~min}$, the curd was cut and transferred to a cotton cloth to expel the excess whey without pressing. The cloth was tied and hung for complete draining, which took about $1 \mathrm{~h}$. Then, the curd was pressed using weights for about $90 \mathrm{~min}$ and the curd was cut to $8 \times$ $12 \times 8 \mathrm{~cm}$. The curds were dry-salted using coarse salt after $24 \mathrm{~h}$ at $6 \pm 1^{\circ} \mathrm{C}$. The next day, the cheese was brine-salted using $14 \% \mathrm{NaCl}$ for about $2 \mathrm{~d}$ (until $\mathrm{pH}$ 
$<5.0)$. Finally, the cheeses were placed into tinplate cans and filled with brine $(7 \% \mathrm{NaCl})$ and ripened for $90 \mathrm{~d}$ at $4 \pm 1^{\circ} \mathrm{C}$. Volatile analysis was performed at $1,30,60$, or $90 \mathrm{~d}$ of ripening; sensory evaluation was conducted only at $90 \mathrm{~d}$ of ripening. Three replicate trials were undertaken for cheese making.

\section{Volatile Composition by SPME/GC-MS}

Frozen cheese samples were sliced into small granules and placed immediately in glass bottles in a freezer at $-20^{\circ} \mathrm{C}$. A duplicate $3.0 \mathrm{~g}$ portion of each sample was placed in a $15-\mathrm{mL}$ vial, and then $10 \mu \mathrm{L}$ of internal standard containing $81 \mathrm{mg} / \mathrm{kg}$ of 2-methyl-3-heptanone in methanol (Sigma-Aldrich Co., St. Louis, MO) was added to the vial and allowed to equilibrate at $40^{\circ} \mathrm{C}$ for 30 min. Extraction of volatiles was carried out using a solvent-less extraction technique (Pawliszyn, 1997). The method is suitable for the isolation of volatiles from the sample matrix and has been used in various configurations for characterization of samples. Essentially, extraction is achieved by injecting a $2-\mathrm{cm} 50 / 30 \mu \mathrm{m}$ divinylbenzene-carboxen-polydimethylsiloxane (DVB/ CAR/PDMS) fiber (Supelco, Bellefonte, PA) into the vial and exposing it to the headspace for $30 \mathrm{~min}$ at $40^{\circ} \mathrm{C}$. The fiber was positioned at 3.0 scale units in each run. Desorption of the extracted volatiles was carried out on a Shimadzu GC-2010-QP-2010 mass spectrometry system (Shimadzu Corp., Kyoto, Japan) and run in split mode (ratio was 1:20). During desorption, the fiber remained in the injector for $2 \mathrm{~min}$ at $250^{\circ} \mathrm{C}$, with helium as the carrier gas at a flow rate of $1.0 \mathrm{~mL} / \mathrm{min}$. The volatile compounds were separated on a DB-Wax column $(60 \mathrm{~m} \times 0.25 \mathrm{~mm} \times 0.25 \mu \mathrm{m}$; J\&W Scientific, Folsom, CA). The oven was held at $40^{\circ} \mathrm{C}$ for $2 \mathrm{~min}$ (desorption period) and then increased at $5^{\circ} \mathrm{C} / \mathrm{min}$ to $70^{\circ} \mathrm{C}$, where it was held for $1 \mathrm{~min}$. The temperature was then increased at $10^{\circ} \mathrm{C} / \mathrm{min}$ to $240^{\circ} \mathrm{C}$, for a total run time of $30 \mathrm{~min}$. The MS was set to record at 33 to 450 atomic mass units (threshold 1,000) at a sampling rate of $1.11 \mathrm{scans} / \mathrm{s}$. The volatile compounds were identified by calculation of the retention index $(\mathbf{R I})$ of each compound, using an $n$-alkane series $\left(\mathrm{C}_{8}\right.$ to $\left.\mathrm{C}_{20}\right)$ under the same conditions. The peak identifications were based on comparison of the mass spectra of unknown compounds with those in Wiley (7th ed.; John Wiley \& Sons Inc., 2005) and NIST/EPA/NIH 02 (http://www. nist.gov) mass spectral libraries. Identifications were confirmed by comparing retention times with reference standards when available. About 30 authentic standard compounds (Sigma Chemical Co.) were used to confirm volatiles in cheese samples. The RI values were compared with those described in the literature and determined under the same conditions used to identify the compounds. The results were calculated by comparison of the peak area of the internal standard and the unknown compounds. The concentration of each compound was expressed as micrograms per kilogram of sample.

\section{Sensory Evaluation}

The cheeses were evaluated by 10 trained panelists at $90 \mathrm{~d}$ of ripening according to the procedure described by Sahan et al. (2008); however, the scale was multiplied by 2 to increase precision. In this case, the samples were evaluated by criteria appearance (scale $0-10$ ), texture (scale 0-10), flavor (scale 0-10), and quality (scale $0-10$ ). Water and bread were provided to panelists to rinse their mouths between samples. Sensory analysis was conducted in 3 replicate trials, and cheeses were evaluated in duplicate by each panelist.

\section{Statistical Analysis}

An experimental design that incorporated 6 goat milk cheeses ( 2 breeds $\times 3$ starter systems) and 4 ripening points $\times 3$ trials was used to analyze the data from the variables. The ANOVA was performed using the GLM procedure of SAS (SAS Institute, 1999) to compare the volatile composition of goat milk cheeses made using milk from 2 breeds of goat and different starter culture systems (starter-free, thermophilic, and mesophilic). Duncan's multiple-comparison test was used as a guide for paired comparisons of treatment means. The level of significance of differences between treatments was determined at $P<0.05$. For sensory data, the ANOVA was performed and Duncan's test was used to compare means using SAS package program (SAS Institute, 1999). Data from volatile components were also analyzed using multivariate statistical techniques to simplify interpretation of the data from GC-MS. Principal component analysis (PCA) was performed using a covariance matrix and varimax rotation between the cheeses. The concentrations of volatile components (GC-MS) were used as variables. The PCA was carried out using the SPSS package for Windows (version 9.0, SPSS Inc., Chicago, IL).

\section{RESULTS AND DISCUSSION}

\section{Volatile Composition}

The effects of starter cultures and goat breeds on volatile fraction of goat milk cheese samples were evaluated by SPME/GC-MS analysis of volatiles in the cheeses. The relative concentrations of some volatiles, including esters (13), carboxylic acids (7), aldehydes 
Cheese $^{2}$

\begin{tabular}{|c|c|c|c|c|c|c|c|c|c|}
\hline \multirow[b]{2}{*}{ Volatile } & \multirow[b]{2}{*}{ RI } & \multirow{2}{*}{$\begin{array}{l}\text { ID } \\
\operatorname{method}^{1}\end{array}$} & \multirow[b]{2}{*}{ Day } & & & & & & \\
\hline & & & & GK & GM & GT & SK & SM & $\mathrm{ST}$ \\
\hline \multirow[t]{4}{*}{ Methyl acetate } & \multirow[t]{4}{*}{867} & \multirow[t]{4}{*}{ MS, RI } & 1 & $3.55 \pm 0.36^{\mathrm{A}}$ & $4.12 \pm 0.17^{\mathrm{A}}$ & $1.65 \pm 2.33$ & $4.97 \pm 0.20^{, \mathrm{A}}$ & $1.97 \pm 2.78^{, \mathrm{B}}$ & $2.05 \pm 2.89^{\mathrm{B}}$ \\
\hline & & & 30 & $2.94 \pm 0.09^{\mathrm{b}, \mathrm{A}}$ & $4.38 \pm 0.55^{\mathrm{a}, \mathrm{A}}$ & $3.75 \pm 0.86^{\mathrm{ab}}$ & $4.13 \pm 0.21^{\mathrm{ab}, \mathrm{AB}}$ & $3.69 \pm 0.48^{\mathrm{ab}, \mathrm{A}}$ & $3.20 \pm 0.19^{\mathrm{ab}, \mathrm{A}}$ \\
\hline & & & 60 & $1.56 \pm 0.36^{\mathrm{bc}, \mathrm{B}}$ & $2.23 \pm 0.37^{\mathrm{abc}, \mathrm{B}}$ & $3.54 \pm 0.80^{\mathrm{ab}}$ & $1.07 \pm 1.51^{\mathrm{c}, \mathrm{C}}$ & $3.68 \pm 0.49^{\mathrm{ab}, \mathrm{A}}$ & $4.03 \pm 1.13^{\mathrm{a}, \mathrm{A}}$ \\
\hline & & & 90 & $1.58 \pm 0.22^{\mathrm{c}, \mathrm{B}}$ & $2.64 \pm 0.22^{\mathrm{abc}, \mathrm{B}}$ & $2.51 \pm 0.78^{\mathrm{abc}}$ & $2.29 \pm 0.49^{\mathrm{bc}, \mathrm{BC}}$ & $3.12 \pm 0.32^{\mathrm{ab}, \mathrm{A}}$ & $3.75 \pm 0.78^{\mathrm{a}, \mathrm{A}}$ \\
\hline \multirow[t]{4}{*}{ Ethyl acetate } & \multirow{4}{*}{894} & \multirow[t]{4}{*}{ MS, RI } & 1 & $36.95 \pm 3.52^{\mathrm{B}}$ & $50.92 \pm 13.11^{\mathrm{B}}$ & $29.57 \pm 3.28^{\mathrm{C}}$ & $58.36 \pm 9.03^{\mathrm{C}}$ & $43.28 \pm 14.13^{\mathrm{C}}$ & $30.50 \pm 30.78^{\mathrm{B}}$ \\
\hline & & & 30 & $56.33 \pm 5.51^{\mathrm{b}, \mathrm{B}}$ & $87.44 \pm 12.91^{\mathrm{a}, \mathrm{B}}$ & $67.92 \pm 12.67^{\mathrm{ab}, \mathrm{B}}$ & $69.1 \pm 16.39^{\mathrm{ab}, \mathrm{C}}$ & $62.88 \pm 10.78^{\mathrm{ab}, \mathrm{C}}$ & $50.53 \pm 2.64^{\mathrm{b}, \mathrm{B}}$ \\
\hline & & & 60 & $170.64 \pm 13.9^{\mathrm{b}, \mathrm{A}}$ & $207.73 \pm 40.99^{\mathrm{b}, \mathrm{A}}$ & $222.61 \pm 45.04^{\mathrm{b}, \mathrm{A}}$ & $170.87 \pm 5.49^{\mathrm{b}, \mathrm{B}}$ & $289.58 \pm 0.95^{\mathrm{ab}, \mathrm{B}}$ & $388.22 \pm 99.62^{\mathrm{a}, \mathrm{A}}$ \\
\hline & & & 90 & $194.76 \pm 17.60^{\mathrm{bc}, \mathrm{A}}$ & $243.83 \pm 17.89^{\mathrm{bc}, \mathrm{A}}$ & $254.95 \pm 41.17^{\mathrm{c}, \mathrm{A}}$ & $256.94 \pm 57.56^{\mathrm{bc}, \mathrm{A}}$ & $375.04 \pm 40.32^{\mathrm{a}, \mathrm{A}}$ & $319.82 \pm 18.59^{\mathrm{ab}, \mathrm{A}}$ \\
\hline \multirow{3}{*}{ Methyl propanoate } & \multirow[t]{3}{*}{912} & \multirow{3}{*}{ MS, RI } & 1 & $2.65 \pm 3.74$ & $6.23 \pm 0.22^{\AA}$ & $1.94 \pm 2.75^{\mathrm{B}}$ & $6.49 \pm 0.18^{\mathrm{A}}$ & $2.17 \pm 3.07$ & $2.32 \pm 3.28$ \\
\hline & & & 30 & $4.25 \pm 0.18$ & $2.77 \pm 3.92^{\mathrm{B}}$ & $5.45 \pm 1.15^{\mathrm{AB}}$ & $5.27 \pm 0.26^{\mathrm{B}}$ & $6.05 \pm 1.40$ & $2.43 \pm 3.43$ \\
\hline & & & 60 & $1.83 \pm 0.62^{\mathrm{d}}$ & $4.90 \pm 0.28^{\mathrm{b}, \mathrm{B}}$ & $6.64 \pm 0.08^{\mathrm{a}, \mathrm{A}}$ & $\mathrm{ND}^{3}$ & $4.40 \pm 1.42^{\mathrm{bc}}$ & $2.99 \pm 0.33^{\mathrm{cd}}$ \\
\hline \multirow{5}{*}{ Methyl butanoate } & \multirow{5}{*}{988} & \multirow{5}{*}{ MS, RI } & 90 & $1.65 \pm 0.11$ & $4.19 \pm 2.20^{\mathrm{B}}$ & $2.71 \pm 1.13^{\mathrm{AB}}$ & $1.81 \pm 0.09^{\mathrm{C}}$ & $2.40 \pm 0.30$ & $3.09 \pm 0.17$ \\
\hline & & & 1 & $12.00 \pm 1.06^{\mathrm{A}}$ & $12.53 \pm 0.77^{\mathrm{A}}$ & $5.08 \pm 4.57$ & $11.72 \pm 0.21^{\mathrm{A}}$ & $4.45 \pm 6.30^{\mathrm{B}}$ & $5.45 \pm 7.71^{\mathrm{B}}$ \\
\hline & & & 30 & $9.22 \pm 0.00^{\mathrm{AB}}$ & $10.71 \pm 0.23^{\mathrm{AB}}$ & $10.63 \pm 1.56$ & $11.65 \pm 0.25^{\mathrm{A}}$ & $9.89 \pm 0.65^{\mathrm{A}}$ & $9.35 \pm 1.73^{\mathrm{A}}$ \\
\hline & & & 60 & $7.13 \pm 1.61^{\mathrm{B}}$ & $8.09 \pm 0.72^{\mathrm{C}}$ & $9.96 \pm 2.19$ & $5.68 \pm 4.65^{\mathrm{B}}$ & $9.00 \pm 1.27^{\mathrm{A}}$ & $11.05 \pm 2.87^{\mathrm{A}}$ \\
\hline & & & 90 & $7.50 \pm 0.58^{\mathrm{ab}, \mathrm{B}}$ & $9.74 \pm 1.41^{\mathrm{b}, \mathrm{BC}}$ & $8.36 \pm 2.66^{\mathrm{b}}$ & $8.39 \pm 0.92^{\mathrm{b}, \mathrm{B}}$ & $8.52 \pm 1.14^{\mathrm{b}, \mathrm{A}}$ & $12.28 \pm 1.05^{\mathrm{a}, \mathrm{A}}$ \\
\hline Methyl 2-methyl & \multirow[t]{4}{*}{1,012} & \multirow{4}{*}{ MS, RI } & 1 & $1.02 \pm 1.44^{\mathrm{ab}}$ & $2.14 \pm 0.28^{\mathrm{a}}$ & $0.65 \pm 0.92^{\mathrm{ab}}$ & $1.72 \pm 0.05^{\mathrm{ab}, \mathrm{A}}$ & $0.57 \pm 0.80^{\mathrm{ab}, \mathrm{B}}$ & ND \\
\hline \multirow[t]{3}{*}{ butanoate } & & & 30 & $0.70 \pm 0.98$ & $0.87 \pm 1.22$ & $1.72 \pm 0.36$ & $1.86 \pm 0.06^{\mathrm{A}}$ & $1.96 \pm 0.37^{\mathrm{A}}$ & $0.95 \pm 1.35^{\mathrm{B}}$ \\
\hline & & & 60 & $1.48 \pm 0.43^{\mathrm{ab}}$ & $1.78 \pm 0.21^{\mathrm{ab}}$ & $2.05 \pm 0.29^{\mathrm{a}}$ & ND & $1.70 \pm 0.25^{\mathrm{ab}, \mathrm{AB}}$ & $1.37 \pm 0.06^{\mathrm{b}, \mathrm{B}}$ \\
\hline & & & 90 & $0.65 \pm 0.92^{\mathrm{c}}$ & $1.87 \pm 0.39^{\mathrm{a}}$ & $1.97 \pm 0.47^{\mathrm{a}}$ & $1.30 \pm 0.08^{\mathrm{b}, \mathrm{B}}$ & $\mathrm{ND}$ & $1.96 \pm 0.13^{\mathrm{a}, \mathrm{A}}$ \\
\hline \multirow[t]{4}{*}{ Ethyl butanoate } & \multirow[t]{4}{*}{1,036} & MS, RI & 1 & $5.92 \pm 0.16^{\mathrm{a}, \mathrm{B}}$ & $0.94 \pm 0.36^{\mathrm{b}, \mathrm{B}}$ & $1.06 \pm 0.12^{\mathrm{b}, \mathrm{AB}}$ & $4.58 \pm 0.78^{\mathrm{a}, \mathrm{B}}$ & $0.69 \pm 0.97^{\mathrm{b}, \mathrm{B}}$ & $1.13 \pm 1.59^{\mathrm{b}, \mathrm{B}}$ \\
\hline & & & 30 & $11.19 \pm 0.35^{\mathrm{a}, \mathrm{AB}}$ & $3.53 \pm 0.44^{\mathrm{c}, \mathrm{B}}$ & $2.44 \pm 0.11^{\mathrm{c}, \mathrm{A}}$ & $3.54 \pm 0.60^{\mathrm{c}, \mathrm{B}}$ & $2.46 \pm 0.49^{\mathrm{c}, \mathrm{A}}$ & $5.65 \pm 1.67^{\mathrm{b}, \mathrm{A}}$ \\
\hline & & & 60 & $11.30 \pm 0.35^{\mathrm{a}, \mathrm{AB}}$ & $2.06 \pm 1.24^{\mathrm{b}, \mathrm{B}}$ & $1.25 \pm 0.04^{\mathrm{b}, \mathrm{AB}}$ & $12.65 \pm 2.93^{\mathrm{a}, \mathrm{A}}$ & $2.86 \pm 2.02^{\mathrm{b}, \mathrm{A}}$ & $3.74 \pm 1.26^{, \mathrm{AB}}$ \\
\hline & & & 90 & $18.89 \pm 6.39^{\mathrm{a}, \mathrm{A}}$ & $5.05 \pm 4.53^{\mathrm{bc}, \mathrm{A}}$ & $0.76 \pm 1.08^{\mathrm{c}, \mathrm{B}}$ & $12.46 \pm 3.19^{\mathrm{ab}, \mathrm{A}}$ & $3.05 \pm 0.01^{\mathrm{c}, \mathrm{A}}$ & $2.68 \pm 1.58^{\mathrm{c}, \mathrm{AB}}$ \\
\hline Butyl acetate & 1,073 & MS, RI & 30 & ND & ND & ND & ND & $0.38 \pm 0.53$ & ND \\
\hline & & & 90 & ND & $0.91 \pm 0.05$ & ND & ND & ND & ND \\
\hline Ethyl hexanoate & 1,233 & MS, RI & 60 & $2.49 \pm 3.52^{\mathrm{B}}$ & ND & ND & $2.47 \pm 3.5$ & ND & ND \\
\hline & & & 90 & $8.89 \pm 2.67^{\mathrm{a}, \mathrm{A}}$ & ND & ND & ND & $0.65 \pm 0.22^{\mathrm{b}}$ & ND \\
\hline Butyl 2-propanoate & 1,350 & MS, RI & 60 & ND & ND & $0.14 \pm 0.19$ & ND & ND & ND \\
\hline & & & 90 & ND & ND & $0.11 \pm 0.15$ & ND & ND & ND \\
\hline Octyl acetate & 1,383 & MS, RI & 1 & ND & ND & ND & ND & $11.01 \pm 1.55^{\mathrm{b}}$ & $15.99 \pm 0.21^{\mathrm{a}}$ \\
\hline & & & 30 & ND & $16.38 \pm 4.07^{\mathrm{a}}$ & ND & $12.05 \pm 1.01^{\mathrm{b}}$ & ND & $9.32 \pm 0.24^{\mathrm{b}}$ \\
\hline & & & 60 & ND & ND & ND & $16.52 \pm 2.86^{\mathrm{a}}$ & ND & $14.10 \pm 4.35^{\mathrm{a}}$ \\
\hline & & & 90 & ND & ND & ND & $11.38 \pm 3.17$ & $11.77 \pm 1.47$ & $13.78 \pm 3.31$ \\
\hline Ethyl octanoate & 1,435 & MS, RI & 1 & ND & ND & ND & $14.46 \pm 2.17^{\mathrm{a}, \mathrm{A}}$ & ND & ND \\
\hline & & & 30 & ND & ND & ND & ND & ND & ND \\
\hline & & & 60 & $1.93 \pm 0.03^{\mathrm{b}, \mathrm{B}}$ & ND & ND & $2.62 \pm 0.72^{\mathrm{b}, \mathrm{B}}$ & $12.60 \pm 0.55^{\mathrm{a}}$ & ND \\
\hline & & & 90 & $4.86 \pm 2.49^{\mathrm{a}, \mathrm{A}}$ & ND & ND & $2.27 \pm 0.60^{\mathrm{b}}$ & ND & ND \\
\hline 2-Hydroxy-4 methyl & 1,481 & MS, RI & 1 & $3.93 \pm 2.53$ & ND & ND & $19.45 \pm 2.43$ & ND & ND \\
\hline methyl pentanoate & & & 30 & ND & ND & ND & ND & ND & $1.86 \pm 0.37$ \\
\hline & & & 60 & ND & ND & ND & ND & ND & ND \\
\hline & & & 90 & ND & ND & ND & ND & ND & ND \\
\hline
\end{tabular}


(6), ketones (8), alcohols (14) and miscellaneous compounds (12), are given in Tables 1 to 6 .

Esters. Esters were one of the most important and most abundant chemical compounds isolated from goat's milk cheese (Table 1). The importance of these compounds is related to their low perception threshold and contribution to cheese as fruity and floral notes (Molimard and Spinnler, 1996). Esters contribute to cheese flavor by reducing the sharpness of fatty acids and the bitterness of amines (Pinho et al., 2003). Some esters such as ethyl acetate, ethyl butanoate, methyl butanoate, and methyl propanoate were predominant in the cheese, and concentrations of ethyl acetate significantly increased during ripening $(P<0.05)$. Agerelated changes (increases or decreases) were observed in most compounds during ripening. Effects of breeds or starter culture system significantly influenced concentrations of ethyl acetate, ethyl butanoate, methyl lactate, and methyl propanoate, as shown in Table 1. These increases in ester concentrations may be due to the esterase activity of lactic acid bacteria via alcoholysis in aqueous systems (Liu et al., 2004; Holland et al., 2005). Concentrations of ethyl ester were higher in starter-free cheeses (GK or SK) than in the cheeses made using starter cultures (GM, GT, SM, or ST). Higher levels of ethyl esters in these cheeses (GK or SK) may be due to the action of nonstarter lactic acid bacteria present in the starter-free cheeses. The ethyl esters were also the main esters found in other goat milk or other types of milk cheeses (Moio and Addeo, 1998; McSweeney and Sousa, 2000; Ortigos et al., 2005; Bontinis et al., 2008).

Carboxylic Acids. The carboxylic acids are not only aroma compounds themselves, but they act as precursors of other aroma compounds, such as methyl ketones, alcohols, lactones, aldehydes, and esters (Collins et al., 2003). Carboxylic acids were found at high concentrations in goat milk cheeses (Table 2), as has been reported in other goat milk cheeses (Saldo et al., 2002; Carunchia Whetstine et al., 2003; Delgado et al., 2011b; Bontinis et al., 2012). Acetic, decanoic, hexanoic, and octanoic acids were the most abundant acids in cheeses, especially after $90 \mathrm{~d}$ of ripening. Three main biochemical pathways are present in the formation of carboxylic acid: proteolysis (breakdown of caseins to peptides and amino acids, and subsequent catabolism of amino acids), lipolysis (formation of fatty acids by hydrolysis of triglycerides), and glycolysis (fermentation of lactose to lactate and then formation of acetic and propanoic acids, and so on) reactions (McSweeney and Sousa, 2000). The use of Turkish Saanen and Gokceada breeds in the manufacture of cheeses significantly influenced the concentrations of carboxylic acids in various stages of maturation (Table 2). Moreover, the use of starter 
Table 2. Carboxylic acids (mean $\pm \mathrm{SD}, \mu \mathrm{g} / \mathrm{kg}$ ) in Gokceada goat cheeses made from different breeds and starter culture systems during $90 \mathrm{~d}$ of ripening

ฉ

\begin{tabular}{lcl} 
Volatile & RI & $\begin{array}{l}\text { method } \\
\text { Acetic acid }\end{array}$ \\
\hline 1,455 & MS, RI, AS
\end{tabular}

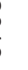

Butanoic acid

1,632 MS, RI, AS

3-Methylbutanoic acid $\quad 1,673 \quad$ MS, RI

Hexanoic acid (caproic) 1,850 MS, RI, AS

\begin{tabular}{ccc} 
GK & GM \\
\hline 1 & $92.12 \pm 16.90^{\mathrm{a}, \mathrm{B}}$ & $4.79 \pm 1.15^{\mathrm{c}, \mathrm{B}}$
\end{tabular}

Chese

Heptanoic acid $\quad 1,956 \quad$ MS, RI

Octanoic acid (caprylic) 2,059 MS, RI, AS

1
30
60
90

$\begin{array}{rr}92.12 \pm 16.90^{\mathrm{a}, \mathrm{B}} & 4.79 \pm 1.15^{\mathrm{c}, \mathrm{B}} \\ 65.31 \pm 11.51^{\mathrm{a}, \mathrm{B}} & 7.50 \pm 3.60^{\mathrm{c}, \mathrm{B}} \\ 49.76 \pm 4.02^{\mathrm{a}, \mathrm{B}} & 5.72 \pm 1.31^{\mathrm{b}, \mathrm{B}} \\ 214.66 \pm 76.59^{\mathrm{a}, \mathrm{A}} & 28.37 \pm 2.00^{\mathrm{b}, \mathrm{A}}\end{array}$

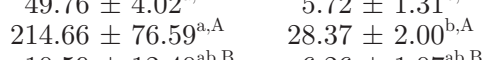

$\begin{array}{rr}10.59 \pm 12.40^{\mathrm{ab}, \mathrm{B}} & 6.26 \pm 1.07^{\mathrm{ab}, \mathrm{B}} \\ 3.86 \pm 0.82^{\mathrm{c}, \mathrm{B}} & 23.14 \pm 7.37^{\mathrm{ab}, \mathrm{A}}\end{array}$

$3.86 \pm 0.82$

$4.87 \pm 6.89^{\mathrm{b} . \mathrm{B}}$

$35.02 \pm 22.43^{\text {bcd,A }} \quad 18.10 \pm 1.16^{\text {cd,AB }}$

$18.10 \pm \frac{1.16}{\mathrm{ND}^{3}}$

$1.22 \pm 0.11^{\mathrm{a}, \mathrm{B}}$

$1.49 \pm 0.29^{\mathrm{B}}$

$6.40 \pm 3.24^{\mathrm{a}, \mathrm{A}}$

$16.34 \pm 1.09^{\mathrm{c}, \mathrm{B}}$

$16.76 \pm 2.30^{\mathrm{c}, \mathrm{B}}$

$22.67 \pm 2.74^{\mathrm{c}, \mathrm{B}}$

$96.09 \pm 50.63^{\mathrm{ab}, \mathrm{A}}$

ND

ND

$0.67 \pm 0.94$

$15.58 \pm 0.25^{\mathrm{c}, \mathrm{B}}$

$15.31 \pm 1.92^{\mathrm{b}, \mathrm{B}}$

$25.76 \pm 4.49^{\mathrm{c}, \mathrm{B}}$

$82.36 \pm 48.75^{\mathrm{aA}}$

$15.01 \pm 0.44^{\mathrm{b}, \mathrm{B}}$

$11.67 \pm 2.53^{\mathrm{c}, \mathrm{B}}$
$17.10 \pm 4.99^{\mathrm{b}, \mathrm{B}}$

$43.99 \pm 26.16^{\mathrm{ab}, \mathrm{A}}$

$\mathrm{ND}^{3}$
$\mathrm{ND}$
$\mathrm{ND}$
$\mathrm{ND}$

$17.25 \pm 3.04^{\mathrm{c}, \mathrm{B}}$

$76.69 \pm 28.40^{\mathrm{a}, \mathrm{A}}$

$26.68 \pm 5.26^{\mathrm{c}, \mathrm{B}}$

$56.12 \pm 7.03^{\mathrm{b}, \mathrm{AB}}$

ND

ND

ND

$12.77 \pm 2.66^{\mathrm{c}, \mathrm{B}}$

$56.27 \pm 21.81^{\mathrm{a}, \mathrm{A}}$

$13.22 \pm 2.61^{\mathrm{c}, \mathrm{B}}$

$26.63 \pm 2.70^{\mathrm{c}, \mathrm{AB}}$

$13.23 \pm 1.36^{\mathrm{b}, \mathrm{B}}$
$53.70 \pm 15.99^{\mathrm{a}, \mathrm{A}}$

$53.70 \pm 15.99^{\mathrm{a}, \mathrm{A}}$
$11.55 \pm 0.64^{\mathrm{b}, \mathrm{B}}$

$18.64 \pm 3.79^{\mathrm{b}, \mathrm{B}}$

GT

SK

$3.42 \pm 1.27^{\mathrm{c}, \mathrm{AB}}$

$51.61+15.59^{\mathrm{b}, \mathrm{B}}$

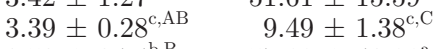

$57.19 \pm 40.91^{\mathrm{a}, \mathrm{B}}$

$6.12 \pm 2.62^{\mathrm{c}, \mathrm{A}}$

$171.54 \pm 13.92^{\mathrm{a}, \mathrm{A}}$

$\mathrm{ND}^{3}$

$9.40 \pm 2.55^{\mathrm{ab}, \mathrm{C}}$

$6.56 \pm 0.07^{\mathrm{c}, \mathrm{B}}$

$26.72 \pm 10.64^{\mathrm{a}, \mathrm{B}}$

$4.30 \pm 0.63^{\mathrm{b}, \mathrm{B}}$
$14.59 \pm 2.78^{\mathrm{d}, \mathrm{A}}$

$14.51 \pm 8.54^{\mathrm{b}, \mathrm{c}}$
$48.89 \pm 6.15^{\mathrm{b}, \mathrm{A}}$

$48.89 \pm 6.15$

ND

ND

ND

$8.06 \pm 1.20^{, \mathrm{B}}$

$17.31 \pm 1.24^{\mathrm{c}, \mathrm{AB}}$

$\mathrm{ND}$
$1.67 \pm 0.10^{\mathrm{B}}$

$1.94 \pm 0.11^{\mathrm{b}, \mathrm{A}}$

$31.94 \pm 6.52^{\mathrm{b}, \mathrm{C}}$

$66.00 \pm 2.05^{\mathrm{ab}, \mathrm{BC}}$

$15.00 \pm 1.16^{\mathrm{c}, \mathrm{AB}} \quad 99.78 \pm 22.41^{\mathrm{b}, \mathrm{AB}}$

$147.16 \pm 39.15^{\mathrm{a}, \mathrm{A}}$

$$
\begin{array}{ll}
\text { ND } & \text { ND } \\
\text { ND } & \text { ND }
\end{array}
$$

ND

ND

$1.02 \pm 0.74$

$1.60 \pm 0.47$

$12.00 \pm 0.56^{\mathrm{c}, \mathrm{B}}$

$15.73 \pm 0.58^{\mathrm{b}, \mathrm{AB}}$

$35.11 \pm 7.85^{\mathrm{b}, \mathrm{B}}$

$52.04 \pm 2.07^{\mathrm{a}, \mathrm{B}}$

$15.77 \pm 0.23^{\mathrm{c}, \mathrm{AB}} \quad 93.28 \pm 1.48^{\mathrm{a}, \mathrm{A}}$

$29.84 \pm 11.91^{\mathrm{c}, \mathrm{A}}$

$12.60 \pm 1.18^{\mathrm{b}, \mathrm{B}}$

$89.22 \pm 24.53^{\mathrm{a}, \mathrm{A}}$

$37.45 \pm 7.15^{\mathrm{a}, \mathrm{B}}$

$38.81 \pm 1.03^{\mathrm{ab}, \mathrm{B}}$

$13.40 \pm 0.93^{\mathrm{b}, \mathrm{B}}$

$38.81 \pm 1.03^{\mathrm{ab}, \mathrm{B}}$
$65.85 \pm 6.63^{\mathrm{a}, \mathrm{A}}$

$18.03 \pm 6.69^{\mathrm{b}, \mathrm{A}}$

$53.64 \pm 12.32^{\mathrm{ab}, \mathrm{AB}}$

$\begin{array}{cc}\text { SM } & \text { ST } \\ 6.28 \pm 8.87^{\mathrm{c}, \mathrm{B}} & 13.28 \pm 4.24^{\mathrm{c}, \mathrm{B}} \\ 4.62 \pm 0.27^{\mathrm{c}, \mathrm{B}} & 38.93 \pm 4.19^{\mathrm{b}, \mathrm{B}} \\ 4.21 \pm 1.73^{\mathrm{b}, \mathrm{B}} & 13.70 \pm 9.63^{\mathrm{ab}, \mathrm{A}} \\ 10.53 \pm 1.55^{\mathrm{c}, \mathrm{A}} & 13.09 \pm 4.51^{\mathrm{c}, \mathrm{B}} \\ 11.94 \pm 3.59^{\mathrm{ab}, \mathrm{C}} & 17.71 \pm 1.53^{\mathrm{a}, \mathrm{A}} \\ 9.84 \pm 0.53^{\mathrm{bc}, \mathrm{C}} & 9.63 \pm 1.73^{\mathrm{bc}, \mathrm{A}} \\ 26.99 \pm 5.34^{\mathrm{ab}, \mathrm{B}} & 72.58 \pm 51.60^{\mathrm{a}, \mathrm{B}} \\ 43.21 \pm 2.05^{\mathrm{bc}, \mathrm{A}} & 74.55 \pm 8.28^{\mathrm{a}, \mathrm{B}} \\ \mathrm{ND} & \mathrm{ND} \\ \mathrm{ND} & \mathrm{ND} \\ \mathrm{ND} & \mathrm{ND} \\ \mathrm{ND} & 42.52 \pm 4.52^{\mathrm{a}, \mathrm{B}} \\ 39.80 \pm 9.38^{\mathrm{ab}, \mathrm{B}} & \mathrm{ND} \\ 22.87 \pm 1.63^{\mathrm{c}, \mathrm{B}} & 40.48 \pm 4.21^{\mathrm{bc}, \mathrm{B}} \\ 78.58 \pm 18.00^{\mathrm{b}, \mathrm{A}} & 119.90 \pm 81.59^{\mathrm{a}, \mathrm{A}} \\ 105.49 \pm 8.01^{\mathrm{ab}, \mathrm{A}} & 136.92 \pm 14.56^{\mathrm{a}, \mathrm{A}} \\ \mathrm{ND} & \mathrm{ND} \\ \mathrm{ND} & \mathrm{ND} \\ \mathrm{ND} & 35.59 \pm 3.83^{\mathrm{a}, \mathrm{B}} \\ 35.89 \pm 1.38^{\mathrm{b}, \mathrm{B}} & 568^{\mathrm{ab}, \mathrm{B}} \\ 14.05 \pm 0.46^{\mathrm{b}, \mathrm{C}} & 35.79 \pm .52 \pm 47.92^{\mathrm{a}, \mathrm{A}} \\ 44.91 \pm 8.37^{\mathrm{b}, \mathrm{AB}} & 76.52 \pm 18.31^{\mathrm{a}, \mathrm{A}} \\ 52.42 \pm 0.76^{\mathrm{b}, \mathrm{A}} & 87.77 \pm 155^{\mathrm{a}, \mathrm{A}} \\ 36.18 \pm 5.89^{\mathrm{a}} & 52.55 \pm 1.72^{\mathrm{b}, \mathrm{B}} \\ 12.52 \pm 0.32^{\mathrm{c}} & 30.71 \pm 73 \pm 53.28^{\mathrm{a}, \mathrm{A}} \\ 50.26 \pm 25.92^{\mathrm{a}} & 69.73 \pm 156^{\mathrm{a}, \mathrm{A}} \\ 43.21 \pm 2.07^{\mathrm{ab}} & 59.96 \pm 15 \\ & \end{array}$

${ }^{\mathrm{a}-\mathrm{d}}$ Means within a row with no common superscript differ $(P<0.05)$.

${ }^{\mathrm{A}-\mathrm{C}}$ Means within a column with no common superscript differ $(P<0.05)$.

${ }^{1}$ Identification methods: MS = mass spectrometry using NIST 07 and Wiley 7 libraries; RI = retention index using alkane series (C8 to C20) under the same chromatographic conditions; AS = authentic standard (Sigma Chemical Co., St. Louis, MO) under the same chromatographic conditions.

${ }^{2} \mathrm{GK}=$ Gokceada breed and starter-free cheese; GM = Gokceada breed and mesophilic starter culture; GT = Gokceada breed and thermophilic starter culture; SK = Turkish Saanen breed and starter-free cheese; SM = Turkish Saanen breed and mesophilic starter culture; ST = Turkish Saanen breed and thermophilic starter culture.

${ }^{3}$ Not detected. 
Table 3. Aldehydes (mean $\pm \mathrm{SD}, \mu \mathrm{g} / \mathrm{kg}$ ) in Gokceada goat cheeses made from different breeds and starter culture systems during $90 \mathrm{~d}$ of ripening

\begin{tabular}{|c|c|c|c|c|c|c|c|c|c|}
\hline \multirow[b]{2}{*}{ Volatile } & \multirow[b]{2}{*}{ RI } & \multirow{2}{*}{$\begin{array}{l}\text { ID } \\
\operatorname{method}^{1}\end{array}$} & \multirow[b]{2}{*}{ Day } & \multicolumn{6}{|c|}{ Cheese $^{2}$} \\
\hline & & & & GK & GM & GT & SK & SM & $\mathrm{ST}$ \\
\hline \multirow[t]{4}{*}{ 3-Methyl butanal } & 922 & MS, RI & 1 & $1.37 \pm 1.94^{\mathrm{b}, \mathrm{B}}$ & $\mathrm{ND}^{3}$ & ND & $6.08 \pm 1.00^{\mathrm{a}, \mathrm{A}}$ & ND & ND \\
\hline & & & 30 & $3.18 \pm 0.09^{\mathrm{a}, \mathrm{AB}}$ & ND & $0.83 \pm 0.31^{\mathrm{b}, \mathrm{B}}$ & ND & $0.70 \pm 0.99^{\mathrm{b}}$ & $1.02 \pm 1.44^{\mathrm{b}}$ \\
\hline & & & 60 & $4.12 \pm 0.70^{\mathrm{a}, \mathrm{AB}}$ & $0.34 \pm 0.49^{\mathrm{b}}$ & $1.01 \pm 0.21^{\mathrm{b}, \mathrm{B}}$ & $2.59 \pm 3.66^{\mathrm{ab}, \mathrm{B}}$ & $0.34 \pm 0.48^{\mathrm{b}}$ & ND \\
\hline & & & 90 & $5.40 \pm 1.08^{\mathrm{a}, \mathrm{A}}$ & ND & $1.71 \pm 0.32^{\mathrm{b}, \mathrm{A}}$ & $5.22 \pm 1.03^{\mathrm{a}, \mathrm{B}}$ & $\mathrm{ND}$ & ND \\
\hline \multirow[t]{4}{*}{ Hexanal } & 1,083 & MS, RI, AS & 1 & $6.30 \pm 0.66^{\mathrm{bc}, \mathrm{B}}$ & $12.15 \pm 2.01^{\mathrm{a}, \mathrm{B}}$ & $3.06 \pm 0.61^{\mathrm{dc}, \mathrm{B}}$ & $4.06 \pm 0.24^{\mathrm{cd}, \mathrm{B}}$ & $9.78 \pm 1.89^{\mathrm{ab}, \mathrm{B}}$ & $1.79 \pm 2.54^{\mathrm{d}, \mathrm{B}}$ \\
\hline & & & 30 & $24.02 \pm 0.98^{\mathrm{a}, \mathrm{A}}$ & $25.19 \pm 0.45^{\mathrm{a}, \mathrm{A}}$ & $5.64 \pm 0.41^{\mathrm{b}, \mathrm{A}}$ & $4.41 \pm 1.10^{\mathrm{b}, \mathrm{B}}$ & $12.26 \pm 1.99^{\mathrm{b}, \mathrm{A}}$ & $6.24 \pm 8.82^{\mathrm{b}, \mathrm{A}}$ \\
\hline & & & 60 & $23.53 \pm 2.54^{\mathrm{b}, \mathrm{A}}$ & $4.27 \pm 1.61^{\mathrm{d}, \mathrm{C}}$ & $2.27 \pm 0.70^{\mathrm{d}, \mathrm{B}}$ & $36.37 \pm 1.93^{\mathrm{a}, \mathrm{A}}$ & $13.11 \pm 1.54^{\mathrm{c}, \mathrm{A}}$ & $5.73 \pm 0.10^{\mathrm{d}, \mathrm{A}}$ \\
\hline & & & 90 & $23.58 \pm 3.20^{\mathrm{b}, \mathrm{A}}$ & $5.41 \pm 0.02^{\mathrm{d}, \mathrm{C}}$ & $2.80 \pm 0.17^{\mathrm{d}, \mathrm{B}}$ & $34.49 \pm 6.42^{\mathrm{a}, \mathrm{A}}$ & $13.32 \pm 2.75^{\mathrm{c}, \mathrm{A}}$ & $3.68 \pm 0.47^{\mathrm{d}, \mathrm{A}}$ \\
\hline \multirow[t]{4}{*}{ Heptanal } & 1,186 & MS, RI & 1 & $0.99 \pm 1.40^{\mathrm{B}}$ & ND & ND & $1.27 \pm 1.80^{\mathrm{B}}$ & ND & ND \\
\hline & & & 30 & $4.28 \pm 0.23^{\mathrm{a}, \mathrm{A}}$ & $4.72 \pm 1.44^{\mathrm{a}, \mathrm{A}}$ & $1.44 \pm 2.04^{\mathrm{bc}}$ & $\mathrm{ND}$ & $3.75 \pm 0.32^{\mathrm{ab}}$ & ND \\
\hline & & & 60 & $2.45 \pm 3.47^{\mathrm{b}, \mathrm{B}}$ & $0.84 \pm 1.19^{\mathrm{b}, \mathrm{B}}$ & $2.00 \pm 0.08^{\mathrm{b}}$ & $8.99 \pm 0.04^{\mathrm{a}, \mathrm{A}}$ & ND & ND \\
\hline & & & 90 & $5.92 \pm 1.45^{\mathrm{A}}$ & ND & ND & $4.13 \pm 5.83^{\mathrm{C}}$ & ND & ND \\
\hline \multirow{4}{*}{ Octanal } & 1,291 & MS, RI & 1 & ND & ND & ND & ND & ND & ND \\
\hline & & & 30 & ND & ND & ND & ND & ND & ND \\
\hline & & & 60 & ND & ND & ND & ND & ND & ND \\
\hline & & & 90 & $5.50 \pm 1.53^{\mathrm{a}}$ & $0.63 \pm 0.89^{\mathrm{b}}$ & ND & ND & ND & ND \\
\hline \multirow[t]{4}{*}{ Nonanal } & 1,385 & MS, RI & 1 & $4.57 \pm 0.21^{\mathrm{ab}}$ & $2.28 \pm 0.43^{\mathrm{bc}, \mathrm{AB}}$ & $1.28 \pm 0.81^{\mathrm{c}, \mathrm{B}}$ & $5.95 \pm 0.79^{\mathrm{a}, \mathrm{B}}$ & $2.16 \pm 0.44^{\mathrm{bc}}$ & $1.33 \pm 1.88^{\mathrm{c}}$ \\
\hline & & & 30 & $3.53 \pm 0.73^{\mathrm{ab}}$ & $3.64 \pm 0.09^{\mathrm{ab}, \mathrm{A}}$ & $0.86 \pm 0.29^{\mathrm{c}, \mathrm{B}}$ & $\mathrm{ND}$ & $2.80 \pm 0.31^{\mathrm{b}}$ & $3.98 \pm 0.69^{\mathrm{a}}$ \\
\hline & & & 60 & $2.23 \pm 3.15^{\mathrm{c}}$ & $0.80 \pm 1.13^{\mathrm{d}, \mathrm{B}}$ & $1.71 \pm 0.86^{\mathrm{c}, \mathrm{A}}$ & $8.85 \pm 1.68^{\mathrm{a}, \mathrm{A}}$ & $3.42 \pm 0.50^{\mathrm{b}}$ & $0.71 \pm 1.01^{\mathrm{d}}$ \\
\hline & & & 90 & $4.86 \pm 1.44^{\mathrm{ab}}$ & $2.94 \pm 0.46^{\mathrm{abc}, \mathrm{A}}$ & $2.23 \pm 0.26^{\mathrm{bc}, \mathrm{A}}$ & $5.56 \pm 0.68^{\mathrm{a}, \mathrm{B}}$ & $3.88 \pm 1.33^{\mathrm{abc}}$ & $1.28 \pm 1.81^{\mathrm{c}}$ \\
\hline \multirow{4}{*}{ Benzaldehyde } & 1,540 & MS, RI & 1 & ND & ND & $\mathrm{ND}$ & $0.54 \pm 0.77^{\mathrm{B}}$ & ND & $1.65 \pm 2.34^{\mathrm{B}}$ \\
\hline & & & 30 & $1.15 \pm 0.38$ & $1.23 \pm 1.73$ & ND & $1.80 \pm 0.34^{\mathrm{AB}}$ & $0.82 \pm 1.15$ & $\mathrm{ND}$ \\
\hline & & & 60 & $1.35 \pm 0.08^{\mathrm{b}}$ & $1.00 \pm 0.31^{\mathrm{b}}$ & ND & ND & $1.46 \pm 0.27^{\mathrm{b}}$ & $2.04 \pm 0.40^{\mathrm{a}, \mathrm{A}}$ \\
\hline & & & 90 & $0.63 \pm 0.88^{\mathrm{b}}$ & $1.54 \pm 0.22^{\mathrm{ab}}$ & $1.76 \pm 0.74^{\mathrm{ab}}$ & $1.98 \pm 0.40^{\mathrm{a}, \mathrm{A}}$ & $1.15 \pm 0.01^{\mathrm{ab}}$ & $2.02 \pm 0.07^{\mathrm{a}, \mathrm{A}}$ \\
\hline
\end{tabular}

${ }^{\mathrm{d}}$ Means within a row with no common superscript differ $(P<0.05)$

${ }^{\mathrm{A}-\mathrm{C}}$ Means within a column with no common superscript differ $(P<0.05)$.

${ }^{1}$ Identification methods: MS = mass spectrometry using NIST 07 and Wiley 7 libraries; RI = retention index using alkane series (C8 to C20) under the same chromatographic conditions; AS = authentic standard (Sigma Chemical Co., St. Louis, MO) under the same chromatographic conditions.

${ }^{2} \mathrm{GK}=$ Gokceada breed and starter-free cheese; GM = Gokceada breed and mesophilic starter culture; GT = Gokceada breed and thermophilic starter culture; SK = Turkish Saanen breed and starter-free cheese; SM = Turkish Saanen breed and mesophilic starter culture; ST = Turkish Saanen breed and thermophilic starter culture.

${ }^{3}$ Not detected. 
Table 4. Ketones (mean $\pm \mathrm{SD}, \mu \mathrm{g} / \mathrm{kg}$ ) in Gokceada goat cheeses made from different breeds and starter culture systems during $90 \mathrm{~d}$ of ripening

\begin{tabular}{|c|c|c|c|c|c|c|c|c|c|}
\hline \multirow[b]{2}{*}{ Volatile } & \multirow[b]{2}{*}{ RI } & \multirow{2}{*}{$\begin{array}{l}\text { ID } \\
\text { method }^{1}\end{array}$} & \multirow[b]{2}{*}{ Day } & \multicolumn{6}{|c|}{ Cheese $^{2}$} \\
\hline & & & & GK & GM & GT & SK & SM & ST \\
\hline \multirow{4}{*}{$\begin{array}{l}\text { 2-Propanone } \\
\text { (Acetone) }\end{array}$} & 858 & MS, RI, AS & 1 & $6.26 \pm 0.68$ & $8.48 \pm 1.50$ & $7.24 \pm 3.81$ & $9.71 \pm 1.61^{\mathrm{A}}$ & $8.17 \pm 3.08^{\mathrm{B}}$ & $4.66 \pm 4.55^{\mathrm{C}}$ \\
\hline & & & 30 & $5.80 \pm 0.75^{\mathrm{b}}$ & $12.46 \pm 2.11^{\mathrm{a}}$ & $8.64 \pm 2.27^{\mathrm{ab}}$ & $7.70 \pm 0.12^{\mathrm{b}, \mathrm{B}}$ & $9.87 \pm 2.50^{\mathrm{ab}, \mathrm{AB}}$ & $5.64 \pm 0.55^{\mathrm{b}, \mathrm{C}}$ \\
\hline & & & 60 & $5.37 \pm 0.88^{\mathrm{c}}$ & $9.27 \pm 2.43^{\mathrm{bc}}$ & $11.51 \pm 2.08^{\mathrm{b}}$ & $6.79 \pm 0.83^{\mathrm{bc}, \mathrm{B}}$ & $17.24 \pm 2.84^{\mathrm{a}, \mathrm{A}}$ & $12.04 \pm 2.83^{\mathrm{ab}, \mathrm{B}}$ \\
\hline & & & 90 & $4.88 \pm 1.15^{\mathrm{c}}$ & $11.19 \pm 0.18^{\mathrm{b}}$ & $8.54 \pm 1.38^{\mathrm{c}}$ & $7.31 \pm 1.40^{\mathrm{c}, \mathrm{B}}$ & $16.23 \pm 2.59^{\mathrm{b}, \mathrm{A}}$ & $31.63 \pm 29.49^{\mathrm{a}, \mathrm{A}}$ \\
\hline \multirow[t]{4}{*}{ 2-Butanone } & 907 & MS, RI, AS & 1 & $23.93 \pm 8.56^{\mathrm{abc}, \mathrm{A}}$ & $32.30 \pm 5.25^{\mathrm{a}, \mathrm{AB}}$ & $12.56 \pm 2.19^{\mathrm{bc}, \mathrm{B}}$ & $29.10 \pm 2.72^{\mathrm{ab}, \mathrm{A}}$ & $15.44 \pm 7.52^{\mathrm{abc}, \mathrm{B}}$ & $9.84 \pm 10.89^{\mathrm{c}}$ \\
\hline & & & 30 & $18.15 \pm 1.14^{\mathrm{c}, \mathrm{AB}}$ & $28.56 \pm 2.79^{\mathrm{b}, \mathrm{AB}}$ & $26.65 \pm 4.31^{\mathrm{bc}, \mathrm{A}}$ & $17.03 \pm 0.07^{\mathrm{c}, \mathrm{B}}$ & $46.09 \pm 5.64^{\mathrm{a}, \mathrm{A}}$ & $6.84 \pm 9.68^{\mathrm{d}}$ \\
\hline & & & 60 & $5.90 \pm 1.53^{\mathrm{d}, \mathrm{BC}}$ & $45.44 \pm 8.49^{\mathrm{a}, \mathrm{A}}$ & $30.66 \pm 4.38^{\mathrm{b}, \mathrm{A}}$ & $3.83 \pm 5.41^{\mathrm{d}, \mathrm{C}}$ & $18.79 \pm 5.24^{\mathrm{bc}, \mathrm{B}}$ & $6.86 \pm 1.50^{\mathrm{cd}}$ \\
\hline & & & 90 & $2.13 \pm 3.01^{\mathrm{b}, \mathrm{C}}$ & $15.26 \pm 6.12^{\mathrm{a}, \mathrm{B}}$ & $7.60 \pm 2.11^{\mathrm{ab}, \mathrm{B}}$ & $6.25 \pm 1.38^{\mathrm{b}, \mathrm{C}}$ & $9.86 \pm 1.14^{\mathrm{ab}, \mathrm{B}}$ & $7.50 \pm 0.75^{\mathrm{ab}}$ \\
\hline \multirow[t]{4}{*}{ 2-Pentanone } & 980 & MS, RI, AS & 1 & $18.27 \pm 0.68$ & $23.06 \pm 1.60$ & $11.92 \pm 4.09^{\mathrm{B}}$ & $19.12 \pm 0.57^{\mathrm{A}}$ & $14.80 \pm 6.71$ & $10.85 \pm 11.89^{\mathrm{B}}$ \\
\hline & & & 30 & $19.21 \pm 0.82^{\mathrm{b}}$ & $25.66 \pm 0.75^{\mathrm{a}}$ & $21.36 \pm 2.67^{\mathrm{b}, \mathrm{A}}$ & $19.38 \pm 1.05^{\mathrm{b}, \mathrm{B}}$ & $20.95 \pm 3.01^{\mathrm{ab}}$ & $17.13 \pm 3.71^{\mathrm{b}, \mathrm{A}}$ \\
\hline & & & 60 & $11.77 \pm 1.11$ & $16.93 \pm 4.21$ & $15.48 \pm 3.37^{\mathrm{AB}}$ & $9.85 \pm 6.99^{\mathrm{A}}$ & $21.10 \pm 4.89$ & $20.09 \pm 5.32^{\mathrm{A}}$ \\
\hline & & & 90 & $22.10 \pm 8.22$ & $22.28 \pm 4.31$ & $13.20 \pm 2.72^{\mathrm{AB}}$ & $15.21 \pm 1.65^{\mathrm{B}}$ & $19.01 \pm 1.48$ & $20.28 \pm 3.47^{\mathrm{A}}$ \\
\hline \multirow[t]{4}{*}{ 2,3-Pentadione } & 1,055 & MS, RI & 1 & $0.35 \pm 0.50^{\mathrm{b}}$ & $3.55 \pm 0.55^{\mathrm{a}}$ & $1.97 \pm 0.72^{\mathrm{ab}, \mathrm{A}}$ & $\mathrm{ND}^{3}$ & ND & $1.10 \pm 1.56^{\mathrm{b}}$ \\
\hline & & & 30 & ND & ND & $2.17 \pm 0.36^{\mathrm{a}, \mathrm{A}}$ & $1.28 \pm 0.18^{\mathrm{b}}$ & $2.25 \pm 0.36^{\mathrm{a}}$ & ND \\
\hline & & & 60 & $0.37 \pm 0.52^{\mathrm{b}}$ & ND & $0.75 \pm 0.06^{\mathrm{a}, \mathrm{B}}$ & ND & ND & ND \\
\hline & & & 90 & ND & ND & ND & ND & ND & ND \\
\hline \multirow[t]{4}{*}{ 2-Heptanone } & 1,183 & MS, RI, AS & 1 & $1.52 \pm 2.15^{\mathrm{b}}$ & $5.34 \pm 1.14^{\mathrm{a}, \mathrm{B}}$ & $3.51 \pm 0.05^{\mathrm{ab}, \mathrm{B}}$ & $4.56 \pm 0.83^{\mathrm{ab}, \mathrm{AB}}$ & $5.97 \pm 1.18^{\mathrm{a}, \mathrm{B}}$ & $5.78 \pm 1.03^{\mathrm{a}}$ \\
\hline & & & 30 & $3.06 \pm 0.23^{\mathrm{b}}$ & $11.40 \pm 0.23^{\mathrm{a}, \mathrm{A}}$ & $4.73 \pm 0.37^{\mathrm{b}, \mathrm{A}}$ & $5.98 \pm 0.19^{\mathrm{b}, \mathrm{A}}$ & $5.48 \pm 0.99^{\mathrm{b}, \mathrm{B}}$ & $3.13 \pm 4.43^{\mathrm{b}}$ \\
\hline & & & 60 & $5.00 \pm 1.50^{\mathrm{bc}}$ & $5.01 \pm 0.22^{\mathrm{bc}, \mathrm{B}}$ & $3.03 \pm 0.45^{\mathrm{d}, \mathrm{B}}$ & $3.45 \pm 0.58^{\mathrm{cd}, \mathrm{BC}}$ & $10.29 \pm 0.63^{\mathrm{a}, \mathrm{A}}$ & $6.02 \pm 0.32^{\mathrm{b}}$ \\
\hline & & & 90 & $4.62 \pm 1.00^{\mathrm{bc}}$ & $5.20 \pm 0.53^{\mathrm{bc}, \mathrm{B}}$ & $2.97 \pm 0.54^{\mathrm{c}, \mathrm{B}}$ & $2.92 \pm 0.42^{\mathrm{c}, \mathrm{C}}$ & $8.73 \pm 1.27^{\mathrm{a}, \mathrm{AB}}$ & $6.89 \pm 2.02^{\mathrm{ab}}$ \\
\hline \multirow[t]{4}{*}{ 2-Octanone } & 1,280 & MS, RI & 1 & $2.01 \pm 2.84$ & ND & ND & ND & ND & ND \\
\hline & & & 30 & ND & ND & ND & ND & ND & $2.18 \pm 3.09$ \\
\hline & & & 60 & ND & ND & ND & ND & ND & ND \\
\hline & & & 90 & ND & ND & ND & ND & ND & ND \\
\hline \multirow{4}{*}{$\begin{array}{l}\text { 3-Hydroxy- } \\
\text { 2-butanone } \\
\text { (acetoin) }\end{array}$} & 1,290 & MS, RI, AS & 1 & $29.99 \pm 3.02^{\mathrm{a}, \mathrm{A}}$ & $6.20 \pm 0.92^{\mathrm{cd}, \mathrm{B}}$ & $3.72 \pm 0.04^{\mathrm{d}, \mathrm{A}}$ & $8.43 \pm 1.47^{\mathrm{cb}, \mathrm{A}}$ & $6.10 \pm 2.11^{\mathrm{cd}}$ & $11.18 \pm 0.10^{\mathrm{b}, \mathrm{A}}$ \\
\hline & & & 30 & $14.92 \pm 0.05^{\mathrm{a}, \mathrm{B}}$ & $8.92 \pm 0.27^{\mathrm{b}, \mathrm{A}}$ & $1.91 \pm 0.19^{\mathrm{e}, \mathrm{B}}$ & $3.18 \pm 0.43^{\mathrm{d}, \mathrm{B}}$ & $6.15 \pm 0.80^{\mathrm{c}}$ & $5.64 \pm 0.49^{\mathrm{c}, \mathrm{B}}$ \\
\hline & & & 60 & ND & $3.78 \pm 1.32^{\mathrm{b}, \mathrm{C}}$ & $1.91 \pm 0.06^{\mathrm{bc}, \mathrm{B}}$ & $4.38 \pm 1.37^{\mathrm{b}, \mathrm{C}}$ & $8.48 \pm 1.24^{\mathrm{a}}$ & $2.89 \pm 1.23^{\mathrm{b}, \mathrm{C}}$ \\
\hline & & & 90 & ND & ND & $3.11 \pm 0.75^{\mathrm{b}, \mathrm{A}}$ & $3.93 \pm 0.03^{\mathrm{b}, \mathrm{B}}$ & $6.85 \pm 1.37^{\mathrm{a}}$ & $5.95 \pm 0.05^{\mathrm{a}, \mathrm{B}}$ \\
\hline \multirow[t]{4}{*}{ 2-Nonanone } & 1,396 & MS, RI, AS & 1 & $0.61 \pm 0.87^{\mathrm{d}}$ & $1.72 \pm 0.35^{\mathrm{bcd}, \mathrm{B}}$ & $1.54 \pm 0.73^{\mathrm{cd}}$ & $2.87 \pm 0.22^{\mathrm{ab}, \mathrm{A}}$ & $2.33 \pm 0.28^{\mathrm{abc}, \mathrm{B}}$ & $3.13 \pm 0.24^{\mathrm{a}}$ \\
\hline & & & 30 & $1.07 \pm 0.11^{\mathrm{c}}$ & $3.65 \pm 0.58^{\mathrm{a}, \mathrm{A}}$ & $0.54 \pm 0.76^{\mathrm{c}}$ & $2.67 \pm 0.33^{\mathrm{ab}, \mathrm{AB}}$ & $1.56 \pm 0.13^{\mathrm{bc}, \mathrm{B}}$ & $2.55 \pm 0.78^{\mathrm{ab}}$ \\
\hline & & & 60 & ND & $1.03 \pm 0.13^{\mathrm{b}, \mathrm{B}}$ & ND & ND & $2.78 \pm 0.23^{\mathrm{a}, \mathrm{A}}$ & $2.41 \pm 0.92^{\mathrm{a}}$ \\
\hline & & & 90 & $0.37 \pm 0.53^{\mathrm{c}}$ & $1.35 \pm 0.26^{\mathrm{bc}, \mathrm{B}}$ & $1.06 \pm 0.45^{\mathrm{c}}$ & $2.26 \pm 0.13^{\mathrm{ab}, \mathrm{B}}$ & $2.62 \pm 0.48^{\mathrm{a}, \mathrm{A}}$ & $2.96 \pm 0.71^{\mathrm{a}}$ \\
\hline
\end{tabular}

${ }^{\mathrm{a}-\mathrm{e}}$ Means within a row with no common superscript differ $(P<0.05)$.

${ }^{\mathrm{A}-\mathrm{C}}$ Means within a column with no common superscript differ $(P<0.05)$.

${ }^{1}$ Identification methods: MS = mass spectrometry using NIST 07 and Wiley 7 libraries; RI = retention index using alkane series (C8 to C20) under the same chromatographic conditions; AS = authentic standard (Sigma Chemical Co., St. Louis, MO) under the same chromatographic conditions.

${ }^{2} \mathrm{GK}=$ Gokceada breed and starter-free cheese; GM = Gokceada breed and mesophilic starter culture; GT = Gokceada breed and thermophilic starter culture; SK = Turkish Saanen breed and starter-free cheese; SM = Turkish Saanen breed and mesophilic starter culture; ST = Turkish Saanen breed and thermophilic starter culture.

${ }^{3}$ Not detected. 
Table 5. Alcohols (mean $\pm \mathrm{SD}, \mu \mathrm{g} / \mathrm{kg}$ ) in Gokceada goat cheeses made from different breeds and starter culture systems during $90 \mathrm{~d}$ of ripening

\begin{tabular}{|c|c|c|c|c|c|c|c|c|c|}
\hline \multirow[b]{2}{*}{ Volatile } & \multirow[b]{2}{*}{ RI } & \multirow{2}{*}{$\begin{array}{l}\text { ID } \\
\text { method }^{1}\end{array}$} & \multirow[b]{2}{*}{ Day } & \multicolumn{6}{|c|}{ Cheese $^{2}$} \\
\hline & & & & GK & GM & GT & SK & $\mathrm{SM}$ & $\mathrm{ST}$ \\
\hline \multirow[t]{4}{*}{ Ethanol } & \multirow[t]{4}{*}{934} & \multirow[t]{4}{*}{ MS, RI, AS } & 1 & $100.43 \pm 11.58^{\mathrm{a}, \mathrm{C}}$ & $22.21 \pm 4.05^{\mathrm{cd}, \mathrm{B}}$ & $7.76 \pm 0.74^{\mathrm{d}, \mathrm{B}}$ & $67.66 \pm 3.59^{\mathrm{b}, \mathrm{B}}$ & $29.28 \pm 13.27^{\mathrm{c}, \mathrm{B}}$ & $8.07 \pm 8.34^{\mathrm{d}, \mathrm{B}}$ \\
\hline & & & 30 & $163.05 \pm 4.30^{\mathrm{a}, \mathrm{BC}}$ & $44.36 \pm 13.15^{\mathrm{c}, \mathrm{A}}$ & $16.69 \pm 2.85^{\mathrm{d}, \mathrm{A}}$ & $17.03 \pm 4.23^{\mathrm{d}, \mathrm{C}}$ & $24.28 \pm 4.67^{\mathrm{d}, \mathrm{B}}$ & $64.98 \pm 8.51^{\mathrm{b}, \mathrm{A}}$ \\
\hline & & & 60 & $238.19 \pm 5.62^{\mathrm{a}, \mathrm{B}}$ & $16.26 \pm 3.91^{\mathrm{d}, \mathrm{B}}$ & $5.52 \pm 1.47^{\mathrm{e}, \mathrm{B}}$ & $183.64 \pm 0.60^{\mathrm{b}, \mathrm{A}}$ & $33.90 \pm 0.13^{\mathrm{c}, \mathrm{A}}$ & $11.61 \pm 3.66^{\mathrm{de}, \mathrm{B}}$ \\
\hline & & & 90 & $351.72 \pm 62.63^{\mathrm{a}, \mathrm{A}}$ & $28.72 \pm 0.40^{\mathrm{c}, \mathrm{AB}}$ & $6.62 \pm 0.96^{\mathrm{d}, \mathrm{B}}$ & $216.73 \pm 34.92^{\mathrm{b}, \mathrm{A}}$ & $37.47 \pm 5.42^{\mathrm{c}, \mathrm{A}}$ & $9.78 \pm 2.50^{\mathrm{d}, \mathrm{B}}$ \\
\hline \multirow{4}{*}{ 2-Butanol } & \multirow{4}{*}{1,020} & \multirow{4}{*}{ MS, RI, AS } & 1 & $6.98 \pm 9.88^{\mathrm{b}, \mathrm{B}}$ & $\mathrm{ND}^{3}$ & ND & $17.24 \pm 1.30^{\mathrm{a}}$ & ND & ND \\
\hline & & & 30 & $24.86 \pm 0.56^{\mathrm{a}, \mathrm{A}}$ & ND & ND & ND & ND & $8.26 \pm 11.68^{\mathrm{b}}$ \\
\hline & & & 60 & $10.35 \pm 14.64^{\mathrm{B}}$ & ND & ND & $15.52 \pm 0.33$ & ND & ND \\
\hline & & & 90 & $22.99 \pm 2.33^{\mathrm{a}, \mathrm{A}}$ & ND & $2.20 \pm 0.10^{\mathrm{b}}$ & $17.71 \pm 6.32^{\mathrm{a}}$ & ND & ND \\
\hline \multirow{4}{*}{ 1-Propanol } & \multirow[t]{4}{*}{1,031} & \multirow{4}{*}{ MS, RI } & 1 & $\mathrm{ND}$ & ND & ND & $0.67 \pm 0.94$ & ND & ND \\
\hline & & & 30 & $2.01 \pm 0.04^{\mathrm{a}}$ & ND & ND & ND & ND & $1.39 \pm 0.13^{\mathrm{b}}$ \\
\hline & & & 60 & ND & ND & ND & $0.92 \pm 1.30$ & ND & ND \\
\hline & & & 90 & $2.25 \pm 0.48$ & ND & ND & ND & ND & ND \\
\hline \multirow{4}{*}{ 2-Methyl-1-propanol } & \multirow{4}{*}{1,086} & \multirow{4}{*}{ MS, RI } & 1 & $8.09 \pm 11.44$ & ND & ND & ND & ND & ND \\
\hline & & & 30 & ND & ND & $2.03 \pm 0.34^{\mathrm{a}}$ & $1.83 \pm 0.55^{\mathrm{a}}$ & ND & ND \\
\hline & & & 60 & $8.54 \pm 12.07^{\mathrm{a}}$ & ND & $1.46 \pm 0.34^{\mathrm{b}}$ & ND & ND & $0.92 \pm 1.30^{\mathrm{b}}$ \\
\hline & & & 90 & $\mathrm{ND}$ & ND & $1.31 \pm 0.53$ & ND & ND & $1.46 \pm 0.27$ \\
\hline \multirow[t]{4}{*}{ 2-Pentanol } & \multirow[t]{4}{*}{1,112} & MS, RI & 1 & $0.63 \pm 0.17$ & ND & ND & ND & ND & ND \\
\hline & & & 30 & ND & ND & ND & $0.47 \pm 0.67$ & ND & ND \\
\hline & & & 60 & ND & ND & ND & $0.67 \pm 0.94^{\mathrm{b}}$ & ND & $2.22 \pm 0.83^{\mathrm{a}}$ \\
\hline & & & 90 & ND & ND & ND & $1.25 \pm 0.36$ & ND & $1.16 \pm 0.15$ \\
\hline 1-Butanol & 1,137 & MS, RI & 1 & $9.13 \pm 1.79$ & ND & ND & $11.94 \pm 0.52$ & ND & ND \\
\hline & & & 30 & $14.82 \pm 0.27$ & ND & ND & $3.58 \pm 0.42$ & ND & $18.18 \pm 6.30$ \\
\hline & & & 60 & $14.67 \pm 1.67^{\mathrm{a}}$ & $5.05 \pm 0.98^{\mathrm{b}, \mathrm{B}}$ & ND & $21.30 \pm 1.67^{\mathrm{a}}$ & ND & ND \\
\hline & & & 90 & $18.37 \pm 2.87^{\mathrm{a}}$ & $25.96 \pm 0.00^{\mathrm{a}, \mathrm{A}}$ & ND & ND & ND & $3.36+0.18^{\mathrm{b}}$ \\
\hline 3-Methyl-1-butanol & 1,201 & MS, RI & 1 & $195.20 \pm 25.25^{\mathrm{b}, \mathrm{B}}$ & $\begin{array}{c}20.30+0.00 \\
\text { ND }\end{array}$ & $25.43 \pm 0.60^{\mathrm{c}, \mathrm{B}}$ & $303.98 \pm 24.64^{\mathrm{a}, \mathrm{A}}$ & $2.41 \pm 3.41^{\mathrm{c}, \mathrm{b}}$ & $29.18 \pm 0.61^{\mathrm{c}, \mathrm{B}}$ \\
\hline & & & 30 & $302.38 \pm 4.90^{\mathrm{a}, \mathrm{A}}$ & $2.04 \pm 2.89^{\mathrm{d}}$ & $46.30 \pm 4.69^{\mathrm{b}, \mathrm{AB}}$ & $35.36 \pm 5.79^{\mathrm{c}, \mathrm{B}}$ & $2.11 \pm 0.07^{\mathrm{d}, \mathrm{B}}$ & $46.97 \pm 6.99^{\mathrm{b}, \mathrm{A}}$ \\
\hline & & & 60 & $290.65 \pm 28.98^{\mathrm{a}, \mathrm{AB}}$ & $1.04 \pm 1.47^{\mathrm{c}}$ & $52.37 \pm 12.24^{\mathrm{b}, \mathrm{A}}$ & $300.39 \pm 9.17^{\mathrm{a}, \mathrm{A}}$ & $1.56 \pm 2.21^{\mathrm{c}, \mathrm{B}}$ & $49.63 \pm 6.75^{\mathrm{b}, \mathrm{A}}$ \\
\hline & & & 90 & $387.15 \pm 63.36^{\mathrm{a}, \mathrm{A}}$ & $1.66 \pm 0.34^{\mathrm{c}}$ & $50.54 \pm 9.70^{\mathrm{b}, \mathrm{A}}$ & $321.88 \pm 63.20^{\mathrm{a}, \mathrm{A}}$ & $4.93 \pm 0.92^{\mathrm{c}, \mathrm{A}}$ & $55.20 \pm 6.00^{\mathrm{b}, \mathrm{A}}$ \\
\hline 1-Pentanol & 1,244 & MS, RI, AS & 1 & $6.65 \pm 1.90^{\mathrm{ab}}$ & $9.73 \pm 20.9^{\mathrm{a}, \mathrm{A}}$ & $4.68 \pm 0.30^{\mathrm{b}, \mathrm{B}}$ & $6.18 \pm 0.16^{\mathrm{ab}, \mathrm{AB}}$ & $2.62 \pm 3.70^{\mathrm{b}, \mathrm{B}}$ & $4.42 \pm 0.18^{\mathrm{b}, \mathrm{AB}}$ \\
\hline & & & 30 & $8.52 \pm 0.76^{\mathrm{ab}}$ & $7.86 \pm 2.11^{\mathrm{abc}, \mathrm{AB}}$ & $7.24 \pm 0.77^{\mathrm{abc}, \mathrm{A}}$ & $4.46 \pm 1.10^{\mathrm{c}, \mathrm{BC}}$ & $8.99 \pm 2.09^{\mathrm{a}, \mathrm{A}}$ & $5.27 \pm 0.22^{\mathrm{bc}, \mathrm{A}}$ \\
\hline & & & 60 & $6.02 \pm 0.55^{\mathrm{abc}}$ & $7.64 \pm 1.30^{\mathrm{a}, \mathrm{AB}}$ & $5.57 \pm 0.95^{\mathrm{bc}, \mathrm{AB}}$ & $6.30 \pm 0.17^{\mathrm{ab}, \mathrm{A}}$ & $5.91 \pm 0.28^{\mathrm{abc}, \mathrm{AB}}$ & $4.20 \pm 0.42^{\mathrm{c}, \mathrm{B}}$ \\
\hline & & & 90 & $7.14 \pm 3.31$ & $6.83 \pm 0.45^{\mathrm{B}}$ & $4.42 \pm 0.99^{\mathrm{B}}$ & $4.30 \pm 0.60^{\mathrm{C}}$ & $5.95 \pm 0.67^{\mathrm{AB}}$ & $5.32 \pm 0.47^{\mathrm{A}}$ \\
\hline 2-Heptanol & 1,311 & MS, RI & 1 & ND & ND & ND & ND & ND & $\mathrm{ND}$ \\
\hline & & & 30 & ND & ND & ND & $1.06 \pm 0.33^{\mathrm{a}}$ & ND & $0.46 \pm 0.65^{\mathrm{b}}$ \\
\hline & & & 60 & $0.37 \pm 0.52$ & ND & ND & $0.89 \pm 1.26$ & ND & $0.95 \pm 1.34$ \\
\hline & & & 90 & $1.87 \pm 0.62$ & ND & ND & $2.03 \pm 0.92$ & ND & $\mathrm{ND}$ \\
\hline 1-Hexanol & 1,346 & MS, RI, AS & 1 & $0.84 \pm 1.18^{\mathrm{b}}$ & $0.41 \pm 0.57^{\mathrm{b}}$ & $1.96 \pm 0.76^{\mathrm{ab}}$ & $1.34 \pm 0.07^{\mathrm{b}, \mathrm{B}}$ & ND & $3.64 \pm 1.28^{\mathrm{a}, \mathrm{A}}$ \\
\hline & & & 30 & $2.37 \pm 0.09^{\mathrm{a}}$ & $1.15 \pm 0.15^{\mathrm{bc}}$ & $1.97 \pm 0.43^{\mathrm{b}}$ & $2.26 \pm 0.63^{\mathrm{a}, \mathrm{A}}$ & $0.82 \pm 0.08^{\mathrm{c}}$ & $1.49 \pm 0.30^{\mathrm{abc}, \mathrm{B}}$ \\
\hline & & & 60 & $1.52 \pm 0.09^{\mathrm{ab}}$ & $0.64 \pm 0.10^{\mathrm{b}}$ & $0.97 \pm 0.01^{\mathrm{b}}$ & $2.50 \pm 0.74^{\mathrm{a}, \mathrm{A}}$ & $0.93 \pm 0.04^{\mathrm{b}}$ & $1.77 \pm 0.80^{\mathrm{ab}, \mathrm{B}}$ \\
\hline & & & 90 & $2.24 \pm 0.69^{\mathrm{ab}}$ & $0.91 \pm 0.07^{\mathrm{c}}$ & $1.38 \pm 0.17^{\mathrm{bc}}$ & $1.73 \pm 0.33^{\mathrm{abc}, \mathrm{B}}$ & $0.98 \pm 0.11^{\mathrm{c}}$ & $2.34 \pm 0.31^{\mathrm{a}, \mathrm{B}}$ \\
\hline 1-Heptanol & 1,449 & $\mathrm{MS}, \mathrm{RI}$ & 1 & $0.29 \pm 0.41^{\mathrm{b}, \mathrm{B}}$ & ND & ND & ND & ND & $1.73 \pm 0.20^{\mathrm{a}, \mathrm{A}}$ \\
\hline & & & 30 & $1.83 \pm 0.12^{\mathrm{a}, \mathrm{A}}$ & $0.93 \pm 0.22^{\mathrm{b}, \mathrm{A}}$ & $0.85 \pm 0.15^{\mathrm{bc}}$ & ND & ND & $0.33 \pm 0.46^{\mathrm{cd}, \mathrm{B}}$ \\
\hline & & & 60 & $1.31 \pm 0.08^{\mathrm{b}, \mathrm{A}}$ & ND & $0.76 \pm 0.13^{\mathrm{b}}$ & $2.83 \pm 0.50^{\mathrm{a}, \mathrm{A}}$ & ND & $1.33 \pm 0.20^{\mathrm{b}, \mathrm{A}}$ \\
\hline & & & 90 & $1.79 \pm 0.58^{\mathrm{a}, \mathrm{A}}$ & $0.36 \pm 0.51^{\mathrm{b}, \mathrm{B}}$ & $0.69 \pm 0.17^{\mathrm{ab}}$ & $1.57 \pm 0.28^{\mathrm{ab}, \mathrm{B}}$ & ND & $1.60 \pm 0.03^{\mathrm{a}, \mathrm{A}}$ \\
\hline 2-Ethyl-1-hexanol & 1,484 & MS, RI & 1 & $3.35 \pm 0.95^{\mathrm{c}, \mathrm{BC}}$ & $2.85 \pm 0.82^{\mathrm{c}, \mathrm{C}}$ & ND & $29.22 \pm 4.57^{\mathrm{a}}$ & $21.80 \pm 2.68^{\mathrm{b}, \mathrm{A}}$ & $31.05 \pm 1.95^{\mathrm{a}, \mathrm{A}}$ \\
\hline & & & 30 & $2.23 \pm 0.23^{\mathrm{c}, \mathrm{C}}$ & $31.45 \pm 5.32^{\mathrm{a}, \mathrm{A}}$ & $2.38 \pm 0.07^{\mathrm{c}}$ & $22.89 \pm 2.03^{\mathrm{b}}$ & $3.16 \pm 0.29^{\mathrm{c}, \mathrm{B}}$ & $19.17 \pm 0.87^{\mathrm{b}, \mathrm{B}}$ \\
\hline & & & 60 & $6.32 \pm 0.34^{\mathrm{b}, \mathrm{A}}$ & $7.30 \pm 1.31^{\mathrm{b}, \mathrm{B}}$ & $4.41 \pm 1.44^{\mathrm{b}}$ & $26.22 \pm 6.86^{\mathrm{a}}$ & $26.14 \pm 2.37^{\mathrm{a}, \mathrm{A}}$ & $29.17 \pm 8.42^{\mathrm{a}, \mathrm{A}}$ \\
\hline & & & 90 & $5.02 \pm 1.41^{\mathrm{b}, \mathrm{AB}}$ & $3.45 \pm 0.97^{\mathrm{b}, \mathrm{C}}$ & $2.86 \pm 0.77^{\mathrm{b}}$ & $23.73 \pm 4.96^{\mathrm{a}}$ & $22.34 \pm 2.79^{\mathrm{a}, \mathrm{A}}$ & $26.94 \pm 4.79^{\mathrm{a}, \mathrm{A}}$ \\
\hline
\end{tabular}

Continued 


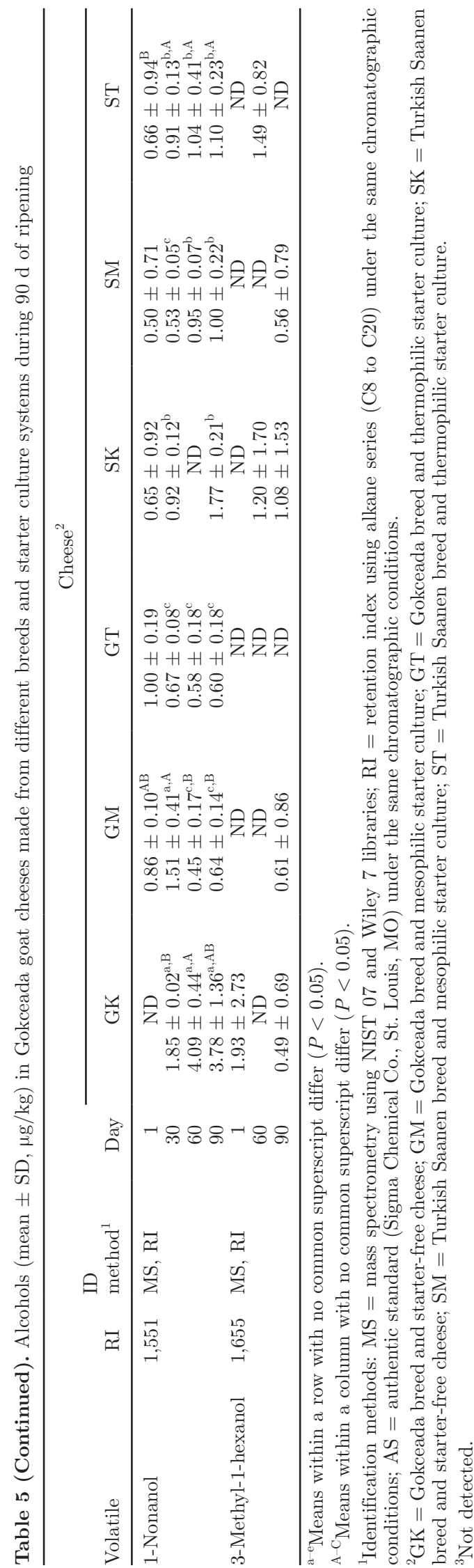

culture caused significant changes in the concentrations of acetic acid during ripening $(P<0.01)$. Both starter culture system and goat breed significantly influenced the concentrations of butanoic acid; cheeses made using Turkish Saanen milk contained higher levels of butanoic acid than did those of the Gokceada breed. Goat breeds also caused significant changes in hexanoic acid concentrations. The increase in hexanoic acid, which is formed by lipolysis and contributes to goat cheese odor, was noticeable in the cheeses, and the cheeses from Gokceada milk had higher levels of hexanoic acid during ripening. Hexanoic acid was predominantly isolated in Ibores, a Spanish goat milk cheese, by Delgado et al. (2011c); however, acetic acid was the most abundant in some other goat milk cheeses, including Xinotyri (Bontinis et al., 2012) and Teleme (Massouras et al., 2006). Octanoic acid was also isolated from goat milk cheese at similar levels as hexanoic acid, and the presence of hexanoic and octanoic acids (also known by their popular names caproic and caprylic acids, respectively) is characteristic of goat milk cheeses. Similarly, levels of octanoic acid were influenced by goat breed. Concentrations of 3 fatty acids (decanoic, hexanoic, and octanoic) may be distinguishing factors for goat breed. Heptanoic and 3-methylbutanoic acids were only detected in starter-free (GK or SK) cheeses, particularly late in maturation (60 or $90 \mathrm{~d}$ ). 3-Methylbutanoic acid (sweaty odor) is produced by metabolism of Ile (Hayaloglu and Brechany, 2007).

Aldehydes. Aldehydes are not major volatile compounds of goat milk cheeses; however, hexanal was abundant in all samples (Table 3). Aldehydes are transitory compounds and do not accumulate in cheese because they are transformed rapidly to alcohols or the corresponding acids (Hayaloglu et al., 2007). A high concentration of aldehydes may cause off-flavors, and the low level of aldehydes may be an indication of good maturation of cheese (Moio and Addeo, 1998). The concentrations of aldehydes (especially heptanal, hexanal, and nonanal) were significantly affected by using milk from different breeds and different starter culture in the manufacture of goat milk cheese (Table $3)$. Their concentrations were also influenced by ripening period, and fluctuations were observed during ripening; however, an increasing trend was observed for the majority of aldehydes. A similar observation was made by Hayaloglu and Brechany (2007). 3-Methylbutanal, which provides malt, oil, or butter aroma to cheese (Serhan et al., 2010), was mainly detected in GK and SK cheeses, and use of starter culture significantly influenced its concentrations. 3-Methylbutanal is formed by Strecker degradation of Leu (Urbach 1995) and is found as potent odor compound in different cheese varieties (Curioni and Bosset, 2002; Hayaloglu 
Table 6. Miscellaneous compounds (mean $\pm \mathrm{SD}, \mu \mathrm{g} / \mathrm{kg}$ ) in Gokceada goat cheeses made from different breeds and starter culture systems during $90 \mathrm{~d}$ of ripening

\begin{tabular}{|c|c|c|c|c|c|c|c|c|c|}
\hline \multirow[b]{2}{*}{ Volatile } & \multirow[b]{2}{*}{ RI } & \multirow{2}{*}{$\begin{array}{l}\text { ID } \\
\text { method }^{1}\end{array}$} & \multirow[b]{2}{*}{ Day } & \multicolumn{6}{|c|}{ Cheese $^{2}$} \\
\hline & & & & GK & GM & GT & SK & $\mathrm{SM}$ & ST \\
\hline \multirow[t]{4}{*}{ Pentane } & 530 & MS, RI & 1 & $5.68 \pm 1.03$ & $8.52 \pm 1.02^{\mathrm{A}}$ & $9.01 \pm 0.41^{\mathrm{A}}$ & $9.43 \pm 0.91^{\mathrm{A}}$ & $4.70 \pm 6.65$ & $4.30 \pm 6.08^{\mathrm{B}}$ \\
\hline & & & 30 & $5.92 \pm 0.47^{\mathrm{ab}}$ & $9.37 \pm 3.17^{\mathrm{a}, \mathrm{A}}$ & $5.50 \pm 1.47^{\mathrm{ab}, \mathrm{AB}}$ & $7.81 \pm 0.65^{\mathrm{ab}, \mathrm{A}}$ & $7.99 \pm 1.45^{\mathrm{ab}}$ & $4.81 \pm 0.28^{\mathrm{b}, \mathrm{B}}$ \\
\hline & & & 60 & $\mathrm{ND}^{3}$ & $4.21 \pm 1.24^{\mathrm{b}, \mathrm{AB}}$ & $2.81 \pm 1.11^{\mathrm{b}, \mathrm{B}}$ & $4.03 \pm 0.73^{\mathrm{b}, \mathrm{B}}$ & $8.62 \pm 1.96^{\mathrm{ab}}$ & $16.39 \pm 7.39^{\mathrm{a}, \mathrm{A}}$ \\
\hline & & & 90 & ND & $2.41 \pm 0.86^{\mathrm{c}, \mathrm{B}}$ & $2.34 \pm 0.70^{\mathrm{c}, \mathrm{B}}$ & $3.86 \pm 0.47^{\mathrm{bc}, \mathrm{B}}$ & $7.08 \pm 0.69^{\mathrm{a}}$ & $5.38 \pm 0.68^{\mathrm{b}, \mathrm{B}}$ \\
\hline \multirow[t]{4}{*}{ Hexane } & 720 & MS. RI & 1 & $418.10 \pm 60.13^{\mathrm{A}}$ & $448.11 \pm 88.44^{\mathrm{A}}$ & $470.32 \pm 14.92^{\mathrm{A}}$ & $541.83 \pm 69.76^{\mathrm{A}}$ & $281.38 \pm 397.94$ & $373.56 \pm 367.58^{\mathrm{A}}$ \\
\hline & & & 30 & $238.79 \pm 44.05^{\mathrm{bc}, \mathrm{B}}$ & $591.51 \pm 103.16^{\mathrm{a}, \mathrm{A}}$ & $231.26 \pm 44.50^{\mathrm{bc}, \mathrm{B}}$ & $384.03 \pm 9.22^{\mathrm{abc}, \mathrm{B}}$ & $427.82 \pm 77.27^{\mathrm{ab}}$ & $262.55 \pm 22.11^{\mathrm{c}, \mathrm{C}}$ \\
\hline & & & 60 & $45.72 \pm 7.27^{\mathrm{b}, \mathrm{C}}$ & $105.81 \pm 28.49^{\mathrm{b}, \mathrm{B}}$ & $58.88 \pm 1.65^{\mathrm{b}, \mathrm{C}}$ & $97.31 \pm 13.96^{\mathrm{b}, \mathrm{C}}$ & $219.99 \pm 13.63^{\mathrm{a}}$ & $223.19 \pm 78.26^{\mathrm{a}, \mathrm{B}}$ \\
\hline & & & 90 & $59.48 \pm 2.84^{\mathrm{c}, \mathrm{C}}$ & $75.78 \pm 7.84^{\mathrm{bc}, \mathrm{B}}$ & $87.29 \pm 23.37^{\mathrm{bc}, \mathrm{C}}$ & $110.19 \pm 12.86^{\mathrm{b}, \mathrm{C}}$ & $190.02 \pm 34.22^{\mathrm{a}}$ & $160.49 \pm 7.79^{\mathrm{a}, \mathrm{C}}$ \\
\hline \multirow[t]{4}{*}{ Heptane } & 744 & MS, RI & 1 & $0.61 \pm 0.86^{\mathrm{B}}$ & $0.69 \pm 0.98^{\mathrm{B}}$ & $0.30 \pm 0.43$ & $0.70 \pm 0.99^{\mathrm{B}}$ & ND & ND \\
\hline & & & 30 & $4.15 \pm 0.30^{\mathrm{b}, \mathrm{A}}$ & $6.25 \pm 3.30^{\mathrm{a}, \mathrm{A}}$ & $1.56 \pm 0.20^{\mathrm{ab}}$ & $1.80 \pm 0.17^{\mathrm{b}, \mathrm{B}}$ & $1.73 \pm 0.44^{\mathrm{b}, \mathrm{B}}$ & $2.60 \pm 0.51^{\mathrm{b}}$ \\
\hline & & & 60 & $1.71 \pm 0.26^{\mathrm{ab}, \mathrm{B}}$ & $1.20 \pm 0.52^{\mathrm{b}, \mathrm{AB}}$ & $0.57 \pm 0.80^{\mathrm{b}}$ & $4.35 \pm 0.38^{\mathrm{a}, \mathrm{A}}$ & $4.20 \pm 2.03^{\mathrm{a}, \mathrm{A}}$ & $1.03 \pm 1.45^{\mathrm{b}}$ \\
\hline & & & 90 & $3.40 \pm 0.40^{\mathrm{ab}, \mathrm{A}}$ & $1.94 \pm 1.22^{\mathrm{bc}, \mathrm{AB}}$ & $1.41 \pm 0.38^{\mathrm{c}}$ & $5.08 \pm 0.58^{\mathrm{a}, \mathrm{A}}$ & $3.67 \pm 0.61^{\mathrm{ab}, \mathrm{A}}$ & $2.06 \pm 0.99^{\mathrm{bc}}$ \\
\hline \multirow{4}{*}{ Octane } & 803 & MS, RI & 1 & ND & $\mathrm{ND}$ & $\mathrm{ND}$ & ND & $0.96 \pm 1.36^{, \mathrm{B}}$ & $\mathrm{ND}$ \\
\hline & & & 30 & $5.40 \pm 0.48^{\mathrm{a}, \mathrm{A}}$ & $4.54 \pm 0.59^{\mathrm{ab}, \mathrm{A}}$ & ND & ND & $2.94 \pm 0.10^{\mathrm{bc}, \mathrm{AB}}$ & $1.29 \pm 1.82^{\mathrm{cd}}$ \\
\hline & & & 60 & ND & ND & ND & $6.33 \pm 0.46^{\mathrm{a}}$ & $5.03 \pm 0.54^{\mathrm{b}, \mathrm{A}}$ & $1.73 \pm 0.73^{\mathrm{c}}$ \\
\hline & & & 90 & $3.07 \pm 0.21^{\mathrm{bc}, \mathrm{B}}$ & $0.77 \pm 1.09^{\mathrm{c}, \mathrm{B}}$ & ND & $7.67 \pm 1.87^{\mathrm{a}}$ & $5.61 \pm 1.53^{\mathrm{ab}, \mathrm{A}}$ & $0.88 \pm 1.24^{\mathrm{c}}$ \\
\hline \multirow{3}{*}{ Tetrahydrofuran } & 868 & MS, RI & 30 & $0.98 \pm 0.00^{\mathrm{a}, \mathrm{B}}$ & $0.62 \pm 0.88^{\mathrm{b}, \mathrm{B}}$ & ND & ND & ND & ND \\
\hline & & & 60 & ND & $0.39 \pm 0.55^{\mathrm{B}}$ & $0.74 \pm 0.10$ & $7.34 \pm 10.39$ & $1.20 \pm 1.69$ & $1.20 \pm 1.69$ \\
\hline & & & 90 & $2.70 \pm 1.56^{\mathrm{A}}$ & $3.48 \pm 3.71^{\mathrm{A}}$ & $0.75 \pm 0.02$ & $0.79 \pm 0.31$ & $1.55 \pm 0.37$ & $1.99 \pm 1.12$ \\
\hline \multirow[t]{4}{*}{ Decane } & 1,008 & MS, RI & 1 & $1.63 \pm 2.30$ & $2.97 \pm 0.63^{\mathrm{AB}}$ & $1.29 \pm 1.82^{\mathrm{B}}$ & $3.61 \pm 0.16^{\mathrm{B}}$ & $1.25 \pm 1.77^{\mathrm{B}}$ & $2.19 \pm 3.10^{\mathrm{B}}$ \\
\hline & 1,000 & NIN, $1 \mathrm{LI}$ & 30 & $3.05 \pm 0.18$ & $1.63 \pm 2.31^{\mathrm{A}}$ & $5.82 \pm 0.51^{\mathrm{A}}$ & $4.71 \pm 1.64^{\mathrm{AB}}$ & $4.56 \pm 1.54^{\mathrm{AB}}$ & $3.95 \pm 5.59^{\mathrm{A}}$ \\
\hline & & & 60 & $8.29 \pm 4.29$ & $5.43 \pm 0.47^{\mathrm{B}}$ & $5.96 \pm 0.19^{\mathrm{A}}$ & ND & $5.66 \pm 0.78^{\mathrm{A}}$ & $4.88 \pm 0.33^{\mathrm{A}}$ \\
\hline & & & 90 & $5.25 \pm 1.50^{\mathrm{ab}}$ & $5.40 \pm 0.31^{\mathrm{ab}, \mathrm{A}}$ & $6.56 \pm 1.44^{\mathrm{a}, \mathrm{A}}$ & $6.12 \pm 0.11^{\mathrm{ab}, \mathrm{A}}$ & $5.00 \pm 0.29^{\mathrm{ab}, \mathrm{A}}$ & $4.01 \pm 0.30^{\mathrm{b}, \mathrm{A}}$ \\
\hline \multirow[t]{4}{*}{$\alpha$-Pinene } & 1,024 & MS, RI & 1 & $3.37 \pm 4.76^{\mathrm{b}, \mathrm{B}}$ & $15.23 \pm 7.52^{\mathrm{a}, \mathrm{A}}$ & $10.93 \pm 6.32^{\mathrm{ab}}$ & ND & ND & ND \\
\hline & & & 30 & $11.80 \pm 1.98^{\mathrm{b}, \mathrm{A}}$ & $22.52 \pm 2.60^{\mathrm{a}, \mathrm{A}}$ & $9.10 \pm 0.76^{\mathrm{b}}$ & ND & ND & ND \\
\hline & & & 60 & $5.19 \pm 2.43^{\mathrm{AB}}$ & $5.99 \pm 0.59^{\mathrm{B}}$ & $4.97 \pm 0.83$ & ND & ND & ND \\
\hline & & & 90 & $6.31 \pm 0.65^{\mathrm{AB}}$ & $3.46 \pm 4.89^{\mathrm{B}}$ & $7.41 \pm 2.27$ & ND & ND & ND \\
\hline \multirow[t]{4}{*}{ Chloroform } & 1.025 & MS, RI & 1 & $2.53 \pm 3.57$ & $2.86 \pm 4.05^{\mathrm{B}}$ & $2.90 \pm 4.10$ & $8.17 \pm 0.71^{\mathrm{A}}$ & $6.93 \pm 2.45$ & $5.13 \pm 7.26^{\mathrm{B}}$ \\
\hline & & & 30 & $2.40 \pm 3.39^{\mathrm{bc}}$ & $12.54 \pm 3.24^{\mathrm{a}, \mathrm{A}}$ & $8.03 \pm 1.76^{\mathrm{ab}}$ & $9.55 \pm 2.05^{\mathrm{ab}, \mathrm{A}}$ & ND & $3.56 \pm 5.03^{\mathrm{bc}, \mathrm{B}}$ \\
\hline & & & 60 & ND & $5.41 \pm 1.97^{\mathrm{bc}, \mathrm{AB}}$ & $4.60 \pm 0.46^{\mathrm{c}}$ & ND & $7.92 \pm 0.52^{\mathrm{b}}$ & $12.28 \pm 1.88^{\mathrm{a}, \mathrm{A}}$ \\
\hline & & & 90 & ND & $\mathrm{ND}$ & $4.87 \pm 0.96^{\mathrm{ab}}$ & $2.17 \pm 3.07^{\mathrm{b}, \mathrm{B}}$ & $7.25 \pm 0.40^{\mathrm{a}}$ & $6.45 \pm 0.45^{\mathrm{a}, \mathrm{A}}$ \\
\hline \multirow[t]{4}{*}{ Toluene } & 1,043 & MS, RI & 1 & $3.16 \pm 4.47$ & $5.56 \pm 2.06^{\mathrm{B}}$ & $4.15 \pm 0.12^{\mathrm{C}}$ & $8.53 \pm 0.71^{\mathrm{A}}$ & $2.83 \pm 4.00^{\mathrm{B}}$ & $5.39 \pm 6.03$ \\
\hline & & & 30 & $7.93 \pm 1.58$ & $10.09 \pm 2.77^{\mathrm{A}}$ & $8.52 \pm 0.32^{\mathrm{A}}$ & $8.63 \pm 0.84^{\mathrm{A}}$ & $10.24 \pm 2.39^{\mathrm{A}}$ & $8.61 \pm 0.31$ \\
\hline & & & 60 & $5.99 \pm 2.78$ & $6.18 \pm 1.96^{\mathrm{B}}$ & $4.83 \pm 0.41^{\mathrm{BC}}$ & $5.00 \pm 0.39^{\mathrm{B}}$ & $9.25 \pm 2.28^{\mathrm{A}}$ & $7.38 \pm 2.22$ \\
\hline & & & 90 & $8.23 \pm 2.20$ & $7.67 \pm 0.71^{\mathrm{B}}$ & $7.38 \pm 1.95^{\mathrm{AB}}$ & $8.18 \pm 1.50^{\mathrm{A}}$ & $9.20 \pm 2.67^{\mathrm{A}}$ & $9.69 \pm 0.11$ \\
\hline \multirow{4}{*}{$\beta$-Pinene } & 1,108 & MS, RI & 1 & $\mathrm{ND}$ & $1.41 \pm 0.28^{\mathrm{a}}$ & $1.06 \pm 0.25^{\mathrm{b}}$ & ND & $\mathrm{ND}$ & ND \\
\hline & & & 30 & $1.26 \pm 0.04^{\mathrm{b}}$ & $1.63 \pm 0.11^{\mathrm{a}}$ & $1.35 \pm 0.03^{\mathrm{b}}$ & ND & ND & ND \\
\hline & & & 60 & $0.78 \pm 0.35^{\mathrm{a}}$ & $0.93 \pm 0.35^{\mathrm{a}}$ & ND & ND & ND & ND \\
\hline & & & 90 & $1.65 \pm 0.75$ & $1.59 \pm 0.50$ & $1.32 \pm 0.42$ & ND & ND & ND \\
\hline \multirow{4}{*}{ Styrene } & 1,263 & MS, RI & 1 & ND & ND & ND & ND & ND & $1.11 \pm 0.20$ \\
\hline & & & 30 & $1.22 \pm 0.37$ & $3.08 \pm 4.36$ & $1.20 \pm 0.04^{\mathrm{A}}$ & $1.58 \pm 0.14^{\mathrm{A}}$ & $1.42 \pm 0.24^{\mathrm{B}}$ & $0.86 \pm 1.22$ \\
\hline & & & 60 & $0.31 \pm 0.43^{\mathrm{b}}$ & $0.69 \pm 0.44^{\mathrm{b}}$ & $\mathrm{ND}$ & $0.18 \pm 0.26^{\mathrm{C}}$ & $4.50 \pm 0.70^{\mathrm{a}, \mathrm{A}}$ & $0.74 \pm 0.20^{\mathrm{b}}$ \\
\hline & & & 90 & $1.38 \pm 1.25^{\mathrm{b}}$ & $1.29 \pm 1.00^{\mathrm{b}}$ & $0.40 \pm 0.05^{\mathrm{b}, \mathrm{B}}$ & $0.83 \pm 0.10^{\mathrm{B}}$ & $3.37 \pm 0.69^{\mathrm{a}, \mathrm{A}}$ & $0.82 \pm 0.19^{\mathrm{b}}$ \\
\hline \multirow{4}{*}{$\begin{array}{l}\text { 2-Methyl-5- } \\
\text { isopropylphenol }\end{array}$} & 2,135 & MS, RI & 1 & $27.61 \pm 27.20$ & $5.22 \pm 7.39$ & $16.91 \pm 10.81$ & ND & $14.58 \pm 20.48$ & $27.32 \pm 7.21^{\mathrm{A}}$ \\
\hline & & & 30 & ND & $6.62 \pm 1.00$ & $3.61 \pm 1.22$ & $3.00 \pm 1.24$ & $\begin{array}{c}14.30 \pm 20.40 \\
2.34 \pm 3.31\end{array}$ & $9.55 \pm 13.50^{\mathrm{B}}$ \\
\hline & & & 60 & $0.57 \pm 0.81$ & ND & $0.74 \pm 1.05$ & $1.64 \pm 2.32$ & ND & $1.13 \pm 1.59$ \\
\hline & & & 90 & $0.73 \pm 1.03$ & ND & $\mathrm{ND}$ & $0.56 \pm 0.80$ & ND & ND \\
\hline
\end{tabular}




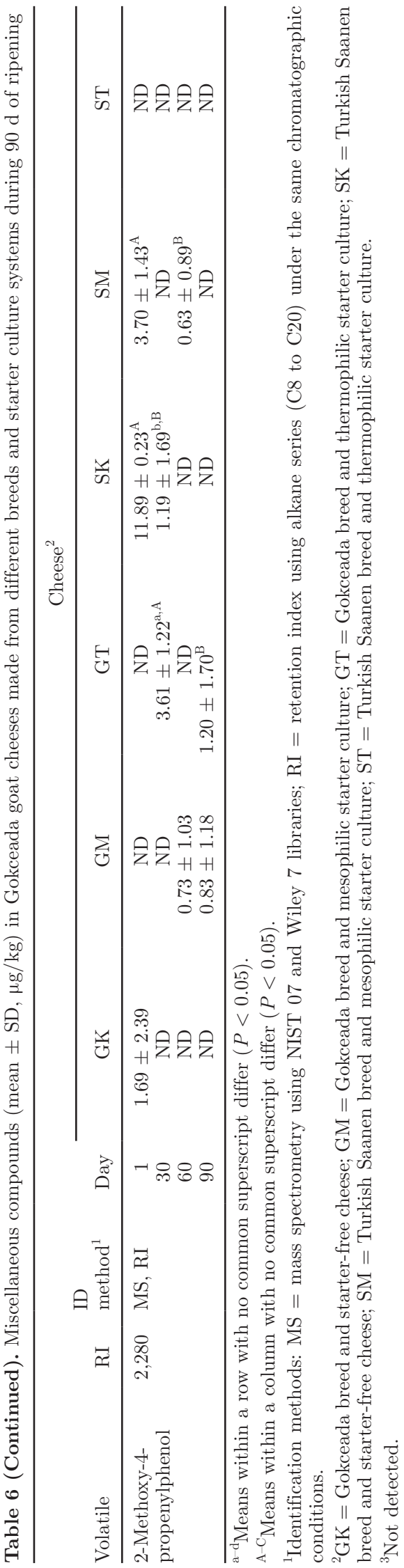

et al., 2007). Benzaldehyde, which has an aromatic note of bitter almond, is commonly found in cheeses and is formed by oxidative reactions of cinnamic acid or phenylacetaldehyde (Molimard and Spinnler, 1996).

Ketones. The major ketones were 2-propanone, 2-butanone, 2-pentanone, and 3-hydroxy-2-butanone (acetoin) and were detected at substantial levels in all samples (Table 4). 3-Hydroxy-2-butanone has also been isolated from a Greek goat cheese (Xinotyri) and its concentration decreased during ripening, probably due to the action of microorganisms (Bintis and Robinson, 2004). Methyl ketones are the principal compounds in blue cheeses and are formed by enzymatic oxidation of free fatty acids to $\beta$-ketoacids and their consequent decarboxylation to methyl ketones, contributing to the pungent aroma (Molimard and Spinnler, 1996; McSweeney and Sousa, 2000). Ketones have unique aromas and contribute cheese flavor because of their low perception threshold. Changes in ketones showed different trends during ripening; however, decreases in their concentrations were usually reported, probably due to the transformation of methyl ketones into secondary alcohols. 2-Butanone, a butter flavor, decreased in some cheese samples during ripening, and the use of different starter culture affected concentrations of 2-butanone. This compound is also the principal ketone in Cheddar (Arora et al., 1995), raw goat milk (Delgado et al., 2011b), and Teleme (Massouras et al., 2006) cheeses. 2-Heptanone, which has an herbaceous odor, was identified in all samples during ripening; its concentration increased at 30 or $60 \mathrm{~d}$ and then decreased at $90 \mathrm{~d}$ (Table 4). The changes observed during ripening were statistically significant and use of milk from different breeds and starter cultures also influenced the concentrations of 2-heptanone. The concentrations of 2-pentanone did not change during ripening except in GK and GT cheeses. In addition to these ketones determined at high levels, 2-octanone and 2-nonanone were also identified in the samples. 2,3-Pentadione was determined in some samples although it disappeared completely toward the end of ripening. Imhof et al. (1994) detected high levels of 2,3-pentadione in cheeses inoculated with thermophilic cultures and suggested that it might be produced by metabolism of Ile.

Alcohols. Alcohols were the main chemical group in the cheeses and contributed to cheese aroma. In total, 14 different alcohols were identified in goat milk cheeses during $90 \mathrm{~d}$ of ripening; the concentrations of some alcohols increased or decreased during ripening (Table 5). Use of different starter culture and milk from different breeds influenced the concentrations of alcohols during ripening. Ethanol, 1-pentanol, and 3 -methyl-1-butanol were the most abundant alcohols in all samples. 3-Methyl-1-butanol may be formed by 
Table 7. Sensory evaluation of Gokceada goat cheese made from different breeds and starter culture systems at $90 \mathrm{~d}$ of ripening

\begin{tabular}{|c|c|c|c|c|c|c|c|c|}
\hline \multirow[b]{2}{*}{ Variable } & \multicolumn{6}{|c|}{ Cheese $^{1}$} & \multirow[b]{2}{*}{ SEM } & \multirow[b]{2}{*}{$P$-value } \\
\hline & GK & GM & GT & SK & SM & $\mathrm{ST}$ & & \\
\hline Appearance & $6.7^{\mathrm{a}}$ & $6.7^{\mathrm{a}}$ & $6.9^{\mathrm{a}}$ & $7.5^{\mathrm{b}}$ & $7.6^{\mathrm{b}}$ & $7.4^{\mathrm{b}}$ & 0.1 & $<0.0001$ \\
\hline Texture & $7.3^{\mathrm{ab}}$ & $7.3^{\mathrm{ab}}$ & $7.5^{\mathrm{a}}$ & $7.1^{\mathrm{abc}}$ & $6.8^{\mathrm{c}}$ & $7.0^{\mathrm{bc}}$ & 0.2 & 0.030 \\
\hline Odor & $7.8^{\mathrm{a}}$ & $7.5^{\mathrm{a}}$ & $7.4^{\mathrm{a}}$ & $6.7^{\mathrm{b}}$ & $6.4^{\mathrm{b}}$ & $6.5^{\mathrm{b}}$ & 0.1 & $<0.0001$ \\
\hline Flavor & $7.6^{\mathrm{ab}}$ & $7.9^{\mathrm{a}}$ & $7.2^{\mathrm{b}}$ & $6.2^{\mathrm{c}}$ & $6.5^{\mathrm{c}}$ & $6.4^{\mathrm{c}}$ & 0.2 & $<0.0001$ \\
\hline Quality & $7.1^{\mathrm{ab}}$ & $7.4^{\mathrm{a}}$ & $6.8^{\mathrm{bd}}$ & $6.0^{\mathrm{c}}$ & $6.5^{\mathrm{c}}$ & $6.2^{\mathrm{cd}}$ & 0.2 & $<0.0001$ \\
\hline
\end{tabular}

${ }^{\mathrm{a}-\mathrm{d}}$ Means within a row with no common superscript differ $(P<0.05)$.

${ }^{1} \mathrm{GK}=$ Gokceada breed and starter-free cheese; GM = Gokceada breed and mesophilic starter culture; GT = Gokceada breed and thermophilic starter culture; SK = Turkish Saanen breed and starter-free cheese; SM = Turkish Saanen breed and mesophilic starter culture; ST = Turkish Saanen breed and thermophilic starter culture.

reduction of 3-methyl-1-butanal through Strecker degradation of Leu (Urbach, 1995; McSweeney and Sousa, 2000). Its concentration increased during ripening and use of starter culture changed the levels of 3-methyl1-butanol. A higher level of 3-methyl-1-butanol is found in goat milk cheeses than in cow milk cheeses (Mollina et al., 1999; Massouras et al., 2006). Ethanol concentrations generally increased during ripening; however, the highest ethanol concentrations were determined at $30 \mathrm{~d}$ in GM, GT, and ST cheeses. Ethanol is mainly produced by the fermentation of lactose and the catabolism of Ala, and it plays an important role in the

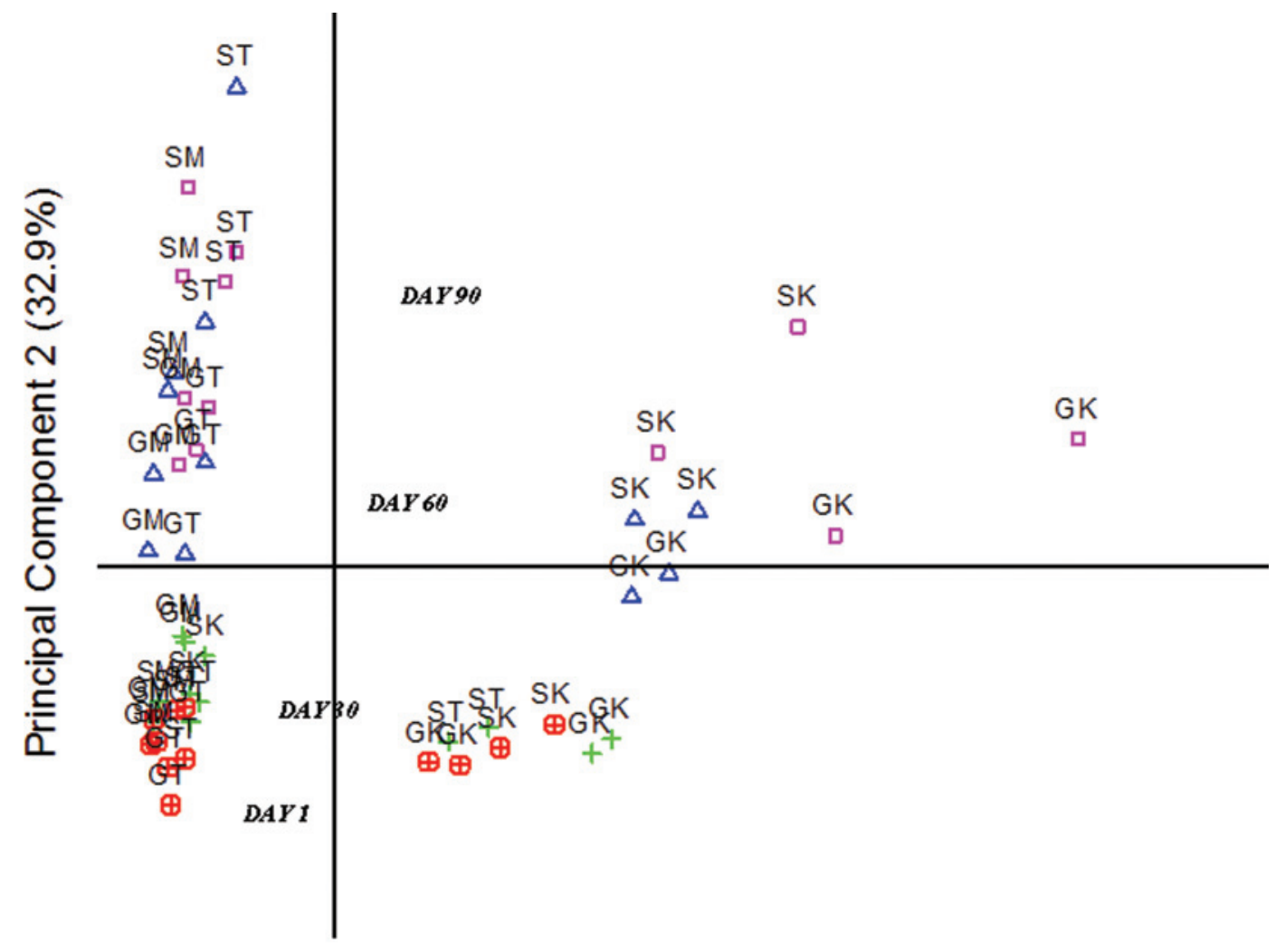

Principal Component 1 (57.8\%)

Figure 1. Score plot of the first 2 principal components of data from GC-MS analysis of cheeses after d $1(\oplus)$, d $30(+)$, d $60(\Delta)$ and d $90(\square)$. GK = Gokceada breed and no starter culture; GM = Gokceada breed and mesophilic starter culture; GT = Gokceada breed and thermophilic starter culture; SK = Turkish Saanen breed and no starter culture; SM = Turkish Saanen breed and mesophilic starter culture; ST = Turkish Saanen breed and thermophilic starter culture. Color version available in the online PDF. 
formation of esters. Ethanol was found as a principal alcohol in other goat milk cheeses (Sable et al., 1997; Attaie, 2009; Bontinis et al., 2012). Interestingly, 2-butanol was identified in GK and SK in large amounts but was not detected in GM and SM cheeses. 2-Butanol is the product of 2-butanone and is formed as follows: diacetyl is reduced to acetoin by bacterial enzymes from raw milk, thereafter to 2,3-butandiol, to 2-butanone, and finally to 2-butanol (Bontinis et al., 2012). The concentration of 1-hexanol was significantly influenced by starter culture system; it did not change during ripening except in ST cheese. 1-Pentanol was another principal alcohol identified and its concentration was significantly influenced by goat breed and starter culture. Very small quantities of 2-butanol, 1-propanol, 2-pentanol, and 2-heptanol were present in GK and SK cheeses (starter-free cheeses) and in ST. The amounts of some alcohol compounds (e.g., 1-hexanol, 1-pentanol, 1-butanol, 2-ethyl-1-hexanol) fluctuated during ripening, probably due to different metabolic pathways available for their formation and to the degradations and conversions continuously taking place among compounds.

Miscellaneous Compounds. Thirteen miscellaneous compounds were identified in goat cheeses, of which hexane was the most abundant (Table 6). Two terpenes, $\alpha$-pinene and $\beta$-pinene, were identified in the cheeses made using milk from the Gokceada breed; their concentration decreased during ripening. These 2 compounds were not identified in cheeses made using milk from the Turkish Saanen breed. Styrene, which has a strong plastic odor, was found in almost all samples. These compounds were also found at low levels in Ibores goat milk cheeses studied by Delgado et al. (2011a). Toluene, which originates from milk or the solvent used for volatile analysis (Molimard and Spinnler, 1996), was detected in low quantities, as in other studies (Hayaloglu et al., 2007; Delgado et al., 2011b; Bontinis et al., 2012). The concentrations of toluene were the same in all samples and were highest at $30 \mathrm{~d}$ of ripening (Table 6). Five hydrocarbons were identified: the concentrations of pentane and hexane decreased during ripening, whereas those of heptane, decane, and octane increased or fluctuated. Two phenols (2-methyl5-isopropylphenol and 2-methoxy-4-propenylphenol) were identified in the cheese samples, and their concentrations decreased significantly during ripening $(P$ $<0.05)$.

\section{PCA of the GC-MS Data}

To understand the effects of starter culture and different goat breeds on volatile profiles of goat milk cheese, PCA was applied to the variables from GC-MS data for 6 batches of goat milk cheeses after 1,30,60, or $90 \mathrm{~d}$ of ripening. Two principal components (PC) accounted for $90.7 \%$ of the total variance: $\mathrm{PC} 1$ and PC2 accounted for 57.8 and $32.9 \%$ of the total variance, respectively (Figure 1). Use of starter culture in the manufacture of goat milk cheese significantly influenced the volatiles in cheeses; starter-free cheeses (GK or SK) were located on the positive side of $\mathrm{PC} 1$, whereas cheeses manufactured using starter cultures (GM, GT, $\mathrm{SM}$, or ST cheeses) were located mainly on the negative side of $\mathrm{PC} 1$; $\mathrm{PC} 2$ distributed the cheeses according to the ripening time. The young cheeses ( 1 and $30 \mathrm{~d}$ ) were located on the negative side of $\mathrm{PC} 2$, whereas older cheeses (60 and $90 \mathrm{~d}$ ) were located on the positive side of PC2. The results indicated that the cheeses had similar volatile profiles at the beginning of ripening time; however, significant changes occurred toward the end of ripening. No clear grouping was observed among the cheeses made from milk of different breeds; thus, goat breed had a marginal effect on volatile profiles of goat cheese. Starter culture system has a greater effect on the volatile profile of goat cheeses than did goat breed.

\section{Sensory Evaluation}

The sensory evaluation results of the 90-d-old goat cheeses are shown in Table 7. Overall, the cheeses were characterized by a salty and acidic taste and had a semi-hard texture. In general, use of milk from the different breeds significantly affected all sensory attributes except for texture. Cheeses from the Gokceada breed had a more satisfactory flavor, odor, and quality than those of Turkish Saanen. This may be because of higher fat $(4.4$ and $3.5 \%)$ and protein $(4.0$ and $3.5 \%)$ contents for Gokceada and Turkish Saanen, respectively. An opposite result was observed for appearance - cheese from the Turkish Saanen breed received higher scores (7.4 to 7.6) than the cheeses from Gokceada breed (6.7 to 6.9). Use of a mesophilic starter culture resulted in higher flavor and quality scores than did use of a thermophilic starter culture. We concluded that cheeses made using mesophilic starter and milk from Gokceada breed had the most satisfactory sensory scores.

\section{CONCLUSIONS}

The use of milk from different goat breeds and use of different starter cultures resulted in good quality cheeses; however, significant differences were observed among cheeses in terms of volatile composition and sensory scores. The main chemical groups in the volatile fractions in the cheeses were ester, alcohols, and carboxylic acids. Use of milk from different goat breeds significantly changed the concentrations of some car- 
boxylic acids, including decanoic, hexanoic, and octanoic acids (also known as capric, caproic, and caprylic acids, respectively). Use of starter culture contributed to the formation of volatile compounds in goat milk cheese. The concentrations of some volatile compounds increased or decreased during ripening, perhaps as a result of metabolisms of microorganisms (e.g., ethanol) or transformation of some compounds (e.g., aldehydes) to others (acids or alcohols). In general, the highest concentrations of volatiles were observed at $30 \mathrm{~d}$ of ripening. The cheeses made using mesophilic starter culture resulted in higher concentrations of volatile compounds and greater sensory scores. In conclusion, milk from the Gokceada breed and mesophilic starter culture should be used in the manufacture of Gokceada goat milk cheese.

\section{ACKNOWLEDGMENTS}

This work was funded by Scientific Research Projects Unit of Canakkale Onsekiz Mart University (BAP Project No: 2010/104). T. Savas (Animal Sciences, Canakkale Onsekiz Mart University, Canakkale, Turkey) is acknowledged for sharing his experience in statistics and animal production.

\section{REFERENCES}

Arora, G., F. Cormier, and B. Lee. 1995. Analysis of odor active volatiles in Cheddar cheese headspace by multidimensional GC/MS/ sniffing. J. Agric. Food Chem. 43:748-752.

Attaie, R. 2009. Quantification of volatile compounds in goat milk Jack cheese using static headspace gas chromatography. J. Dairy Sci. 92:2435-2443.

Bintis, T., and R. K. Robinson. 2004. A study of the effects of adjunct cultures on the aroma compounds of Feta-type cheese. Food Chem. 88:435-441.

Bontinis, T. G., H. Mallatou, E. Alichanidis, A. Kakouri, and J. Samelis. 2008. Physicochemical, microbiological and sensory changes during ripening and storage of Xinotyri, a traditional Greek cheese from raw goat's milk. Int. J. Dairy Technol. 61:229-236.

Bontinis, T. G., H. Mallatou, E. C. Pappa, T. Massouras, and E. Alichanidis. 2012. Study of proteolysis, lipolysis and volatile profile of a traditional Greek goat cheese (Xinotyri) during ripening. Small Rumin. Res. 105:193-201.

Carunchia Whetstine, M. E., Y. Karagul-Yuceer, Y. K. Avsar, and M. A. Drake. 2003. Identification and quantification of character aroma components in fresh Chevre-style goat cheese. J. Food Sci. 68:2441-2447.

Collins, Y. F., P. L. H. McSweeney, and M. G. Wilkinson. 2003. Evidence of a relationship between autolysis of starter bacteria and lipolysis in Cheddar cheese during ripening. J. Dairy Res. 70:105113.

Curioni, P. M. G., and J. O. Bosset. 2002. Key odorants in various cheese types as determined by gas chromatography-olfactometry. Int. Dairy J. 12:959-984.

Delgado, F. J., J. Gonzalez-Crespo, R. Cava, and R. Ramirez. 2011a. Changes in the volatile profile of a raw goat milk cheese treated by hydrostatic high pressure at different stages of maturation. Int. Dairy J. 21:135-141.

Delgado, F. J., J. Gonzalez-Crespo, R. Cava, and R. Ramirez. 2011b. Effect of high-pressure treatment on the volatile profile of a ma- ture raw goat milk cheese with paprika on rind. Innov. Food Sci. Emerg. Technol. 12:98-103.

Delgado, F. J., J. Gonzalez-Crespo, R. Cava, and R. Ramirez. 2011c. Formation of the aroma of a raw goat milk cheese during maturation analysed by SPME-GC-MS. Food Chem. 129:1156-1163.

Engels, W. J. M., R. Dekker, C. De Jong, R. Neeter, and S. Visser. 1997. A comparative study of volatile compounds in the watersoluble fraction of various types of ripened cheese. Int. Dairy J. $7: 255-263$.

Ferreira, I. M. P. L. V. O., O. Pinho, and P. Sampio. 2009. Volatile fraction of DOP "Castelo Branco" cheese: Influence of breed. Food Chem. 112:1053-1059.

Fox, P. F., and J. M. Wallace. 1997. Formation of flavour compounds in cheese. Adv. Appl. Microbiol. 45:17-85.

Hayaloglu, A. A., and E. Y. Brechany. 2007. Influence of milk pasteurization and scalding temperature on the volatile compounds of Malatya, a farmhouse Halloumi-type cheese. Lait 87:39-57.

Hayaloglu, A. A., S. Cakmakci, E. Y. Brechany, K. C. Deegan, and P. L. H. McSweeney. 2007. Microbiology, biochemistry and volatile composition of Tulum cheese ripened in goat's skin or plastic bags. J. Dairy Sci. 90:1102-1121.

Hayaloglu, A. A., and Y. Karagul-Yuceer. 2011. Utilization and characterization of small ruminants' milk and milk products in Turkey: Current status and new perspectives. Small Rumin. Res. 101:73-83.

Holland, R., S.-Q. Liu, V. L. Crow, M. L. Delabre, M. Lubbers, M. Bennet, and G. Norris. 2005. Esterases of lactic acid bacteria and cheese flavour: Milk fat hydrolysis, alcoholysis and esterification. Int. Dairy J. 15:711-718.

Imhof, R., H. Glattli, and J. O. Bosset. 1994. Volatile organic aroma compounds produced by thermophilic and mesophilic mixed strain dairy starter cultures. Lebenson. Wiss. Technol. 27:442-449.

John Wiley \& Sons Inc. 2005. Wiley Registry of Mass Spectral Data. 7th ed. with NIST 2005 Spectral Data. CD-ROM. John Wiley \& Sons Inc., New York, NY.

Liu, S.-Q., R. Holland, and V. L. Crow. 2004. Esters and their biosynthesis in fermented dairy products: A review. Int. Dairy J. 14:923-945.

Massouras, T., E. C. Pappa, and H. Mallatou. 2006. Headspace analysis of volatile flavour compounds of Teleme cheese made from sheep and goat milk. Int. J. Dairy Technol. 59:250-256.

McSweeney, P. L. H., and M. J. Sousa. 2000. Biochemical pathways for the production of flavour compounds in cheese during ripening: A review. Lait 80:293-324.

Moio, L., and F. Addeo. 1998. Grana Padano cheese aroma. J. Dairy Res. 65:317-333.

Molimard, P., and H. E. Spinnler. 1996. Compounds involved in the flavor of surface mold-ripened cheeses: Origins and properties. J. Dairy Sci. 79:169-184.

Mollina, E., M. Ramos, L. Alonso, and R. Lopez-Fandino. 1999. Contribution of low molecular weight water-soluble compounds to the taste of cheeses made of cows', ewes' and goats' milk. Int. Dairy J. 9:613-621.

Ortigos, M., C. Arizcun, P. Torre, and J. M. Izco. 2005. Use of wild Lactobacillus strains in an adjunct culture for a Roncal-type cheese. J. Dairy Res. 72:168-178.

Pawliszyn, J. 1997. Solid Phase Microextraction: Theory and Practice. Wiley-VCH, New York, NY.

Pinho, O., C. Peres, and I. M. P. L. V. O. Ferreira. 2003. Solid-phase microextraction of volatile compounds in "Terrincho" ewe cheese. Comparison of different fibers . J. Chromatogr. A 1011:1-9.

Sable, S., F. Lettellier, and G. Cottenceau. 1997. An analysis of volatile flavour compounds in a soft raw goat milk cheese. Biotechnol. Lett. 19:143-145.

Sahan, N., K. Yasar, A. A. Hayaloglu, O. B. Karaca, and A. Kaya. 2008. Influence of fat replacers on chemical composition, proteolysis, texture profiles, meltability and sensory properties of low-fat Kashar cheese. J. Dairy Res. 75:1-7.

Saldo, J., P. L. H. McSweeney, E. Sendra, A. L. Kelly, and B. Guamis. 2002. Proteolysis in caprine milk cheese treated by high pressure to accelerate cheese ripening. Int. Dairy J. 12:35-44. 
SAS Institute. 1999. User's Guide: Statistics. Version 8.0 ed. SAS Institute Inc., Cary, NC.

Serhan, M., M. Linder, C. Hosri, and J. Fanni. 2010. Changes in proteolysis and volatile fraction during ripening of Darfiyeh, a Lebanese artisanal raw goat's milk cheese. Small Rumin. Res. 90:75-82.

Soryal, K., F. A. Beyene, S. Zeng, B. Bah, and K. Tesfai. 2005. Effect of goat breed and milk composition on yield, sensory quality, fatty acid concentration of soft cheese during lactation. Small Rumin. Res. 58:275-281.

Tolu, C. 2009. Farkli keci genotiplerinde davranis, saglik ve performans ozellikleri uzerine Arastirmalar. PhD Thesis. Canakkale Onsekiz Mart University, Canakkale, Turkey.

Urbach, G. 1995. Contribution of lactic acid bacteria to flavour compound formation in dairy products. Int. Dairy J. 5:877-903. 